\title{
A contribution to the knowledge of the genera Fissocantharis Pic, 1921 and Micropodabrus Pic, 1920 from Taiwan (Coleoptera, Cantharidae)
}

\author{
Limei LI ${ }^{1}$, Lulu ZHANG ${ }^{2}$, Yuxia YANG ${ }^{3, *}$ \& Yûichi OKUSHIMA ${ }^{4, *}$ \\ 1,2,3 The Key Laboratory of Zoological Systematics and Application, \\ College of Life Sciences, Hebei University, Baoding 071002, Hebei Province, China. \\ ${ }^{4}$ Kurashiki Museum of Natural History, Chûô 2-6-1, Kurashiki, Okayama, 710-0046 Japan. \\ ${ }^{1}$ Email: 695163750@qq.com \\ 2Email:2940331171@qq.com \\ *Co-corresponding authors: ${ }^{3}$ yxyang@hbu.edu.cn, ${ }^{4}$ musoku@city.kurashiki.okayama.jp \\ ${ }^{1}$ urn:Isid:zoobank.org:author:EF6832A3-76B9-495E-B552-D304D3CAF494 \\ ${ }^{2}$ urn:lsid:zoobank.org:author:2D7E44B4-1472-43C0-A669-B86433EEA6DE \\ ${ }^{3}$ urn:lsid:zoobank.org:author:CA819BAF-F411-4917-9205-4F1C36AC4DC9 \\ ${ }^{4}$ urn:Isid:zoobank.org:author:BB590861-E5AE-438B-AC0E-A8724F8FAAB5
}

\begin{abstract}
Twenty previously known species of Fissocantharis Pic, 1921 and Micropodabrus Pic, 1920 from Taiwan are illustrated and described with the genitalia of both sexes and or abdominal sternite VIII of female. The following reconfirmed combinations are proposed, Micropodabrus chujoi (Wittmer, 1972), M. mucronata (Wittmer, 1979), M. multicostata (Wittmer, 1982) and M. nodicornis (Wittmer, 1982), which were all originally described in Kandyosilis Pic, 1929. Two new species are described, Fissocantharis nigriceps Y. Yang \& Okushima sp. nov. and Micropodabrus brunneipennis Y. Yang \& Okushima sp. nov., which are provided with the illustrations of aedeagus and photos of male habitus.

Keywords. Fissocantharis, Micropodabrus, new species, reconfirmed combination, Taiwan.

Li L., Zhang L., Yang Y. \& Okushima Y. 2016. A contribution to the knowledge of the genera Fissocantharis Pic, 1921 and Micropodabrus Pic, 1920 from Taiwan (Coleoptera, Cantharidae). European Journal of Taxonomy 243: 1-37. http://dx.doi.org/10.5852/ejt.2016.243
\end{abstract}

\section{Introduction}

At present, the genus Fissocantharis Pic, 1921 (sensu Yang et al. 2009) includes 28 species distributed in Taiwan (Yang et al. 2012). Most species could be distinguished by their characteristic antennae of males, as those from the mainland China and adjacent areas (e.g. Wittmer 1988; Švihla 2004, 2005). However, the aedeagus, which is traditionally the most reliable morphological character to identify the cantharid species, was always neglected or not illustrated in the original publications on this genus (Wittmer 1954, 1972, 1979, 1982, 1993, 1995, 1997). Additionally, the characters of female genitalia and abdominal sternite VIII, which are suggested to be of diagnostic value in determination of the Fissocantharis species (Yang et al. 2014, 2015), have never been known for any Taiwanese species until now. 
In the present study, we illustrate and describe the genitalia of both sexes and/or abdominal sternite VIII of female for 19 previously known species of Fissocantharis at our disposal. As a result, we discover that 4 species should be reconfirmed to Micropodabrus Pic, 1920 (sensu Yang et al. 2009, not Wittmer 1997), including M. chujoi (Wittmer, 1972), M. mucronata (Wittmer, 1979), M. multicostata (Wittmer, 1982) and M. nodicornis (Wittmer, 1982), whose aedeagus are all presented with the laterophyses.

Finally, we discover 2 new species and describe them under the names of Fissocantharis nigriceps Y. Yang \& Okushima sp. nov. and Micropodabrus brunneipennis Y. Yang \& Okushima sp. nov. Based on our results there are now 25 species of Fissocantharis and 6 species of Micropodabrus occurring in Taiwan.

\section{Material and methods}

The holotypes designated in this paper are deposited in the National Museum of Natural Science, Taichung, Taiwan (NMNS), and the other material used in this study are all deposited in the Kurashiki Museum of Natural History, Japan (KURA). The method and format of description and illustrations follow that of Yang et al. (2015).

The abbreviations in the figures are as follows: ag: accessory gland; di: diverticulum; ov: median oviduct; sd: spermathecal duct; sp: spermatheca; va: vagina.

\section{Results}

Class Hexapoda Blainville, 1816

Order Coleoptera Linnaeus, 1758

Superfamily Elateroidea Leach, 1815

Family Cantharidae Imhoff, 1856

Genus Fissocantharis Pic, 1921

Fissocantharis Pic, 1921a: 27.

Cephalomalthinus Pic, 1921b: 5.

Fissopodabrus Pic, 1927: 2.

Kandyosilis Pic, 1929: 70.

Rhagonycha (Harmonycha) Wittmer, 1938: 302.

Javaesilis Pic, 1955: 7.

Stenopodabrus Nakane, 1992: 78.

\section{Diagnosis}

Body small to middle-sized, elongate. Eyes moderately or strongly protruding in male, weakly or moderately in female. Antennae filiform, often present with narrow longitudinal grooves or more or less deformed on middle antennomeres in male, while simple in female. Pronotum subquadrate, subparallelsided or slightly widened posteriorly, anterior margin narrower or as wide as head width across eyes. Legs with all tarsal claws bifid or having triangular basal appendicles in both sexes. Aedeagus: elongate, dorsal plates of parameres conjoint, laterophyses absent. Female genitalia: vagina stout, always abruptly thinned and extended into a slightly long duct at ventroapical portion; diverticulum and spermathecal duct arising from the end of the duct of vagina; diverticulum thin and spiral-tubed, spermatheca composed of one thin and spiral tube; median oviduct always situated in middle of vagina. 
Fissocantharis bicoloriceps (Wittmer, 1995)

Fig. $1 \mathrm{~A}-\mathrm{C}$

Micropodabrus bicoloriceps Wittmer, 1995: 117, figs 12, 13.

Fissocantharis bicoloriceps - Yang et al. 2012: 52.

\section{Material examined}

TAIWAN: 1 ð, Hsinchou, 920 m, 17 Mar. 1996, leg. L.J. Wang (KURA).

\section{Supplementary description}

AEDEAGus (Fig. 1A-C). Ventral process of each paramere wide, slightly narrowed apically, moderately hooked at apex; conjoint dorsal plate of parameres moderately developed, about half length of ventral process and as wide as half of the distance between outer margins of ventral processes, moderately narrowed apically, with straight apical margin.

\section{Remarks}

In the original publication (Wittmer 1995), this species was only illustrated with male antennae. Here, the aedeagus is illustrated and described for the first time.

\section{Distribution}

Taiwan.

Fissocantharis denominata (Wittmer, 1997)

Figs 1D-F, 2A, 5A

Podabrus formosanus Wittmer, 1954: 274, fig. 2.

Micropodabrus taiwanus Wittmer, 1982: 130 (Replacement name for Podabrus formosanus Wittmer, 1954).

Micropodabrus denominatus Wittmer, 1997: 310 (Replacement name for Micropodabrus taiwanus Wittmer, 1982).

Fissocantharis denominata - Yang et al. 2012: 52.

\section{Material examined}

Same data as specimens examined in Yang et al. (2012).

\section{Supplementary description}

AEDEAGus (Fig. 1D-F). Ventral process of each paramere wide, slightly narrowed apically, moderately hooked at apex; conjoint dorsal plate of parameres moderately developed, about half length of ventral process and as wide as one-third of the distance between outer margins of ventral processes, distinctly narrowed apically, with straight apical margin.

AbDOMinal STERNite VIII of FEMALE (Fig. 5A). Slightly and roundly emarginate in middle and on both sides of posterior margin.

INTERNAL ORGAN OF REPRODUCTIVE SYSTEM (Fig. 2A). Vagina stout, abruptly thinned and extended into a short duct at ventroapical portion; diverticulum and spermathecal duct arising from the end of the duct of vagina; diverticulum moderately long, spiral and distinctly thinned apically; spermathecal duct slightly shorter than diverticulum and slightly thinner than basal portion of diverticulum; spermatheca 

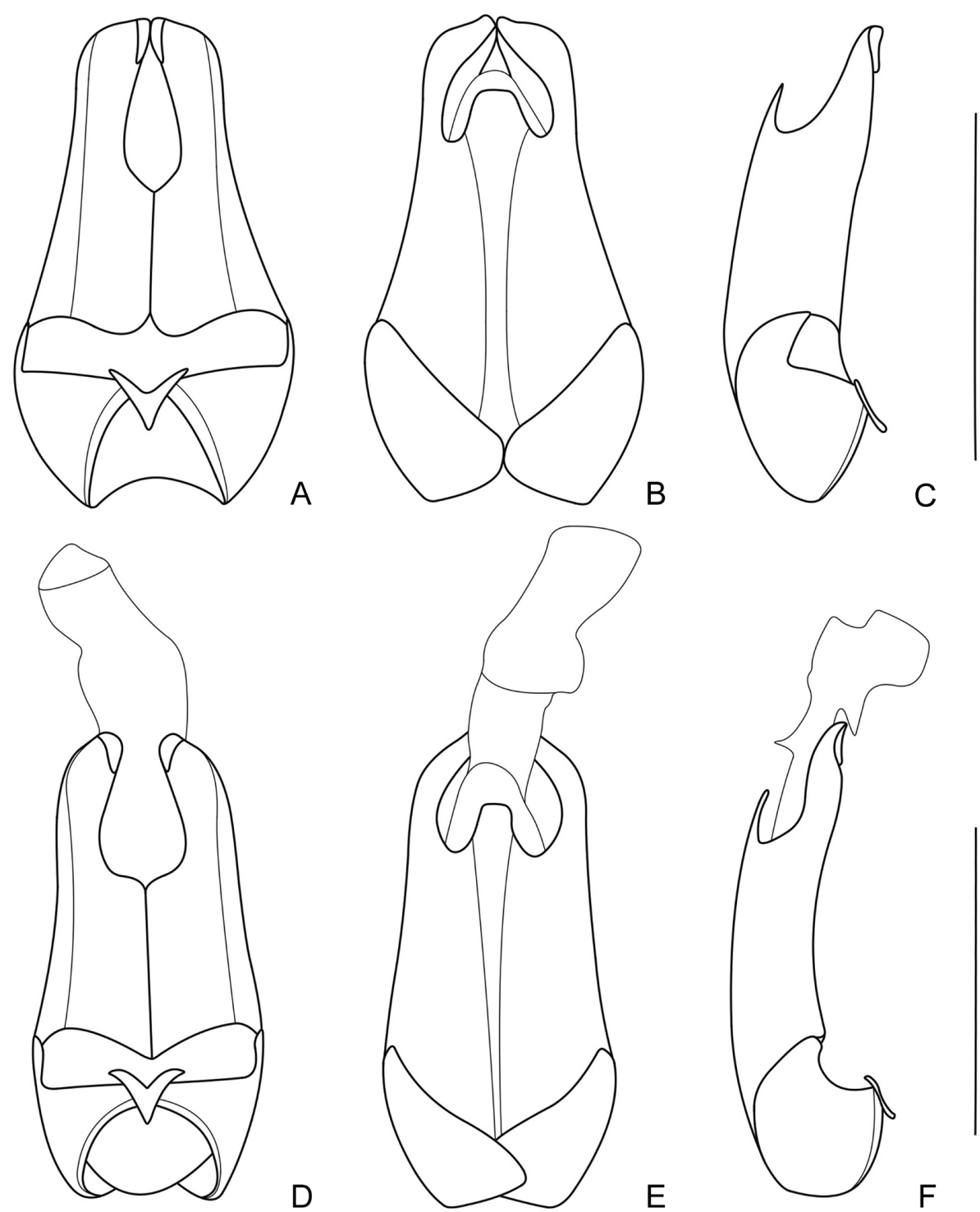

C
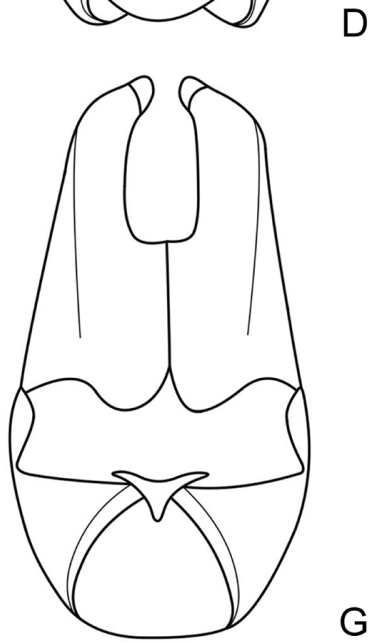

G

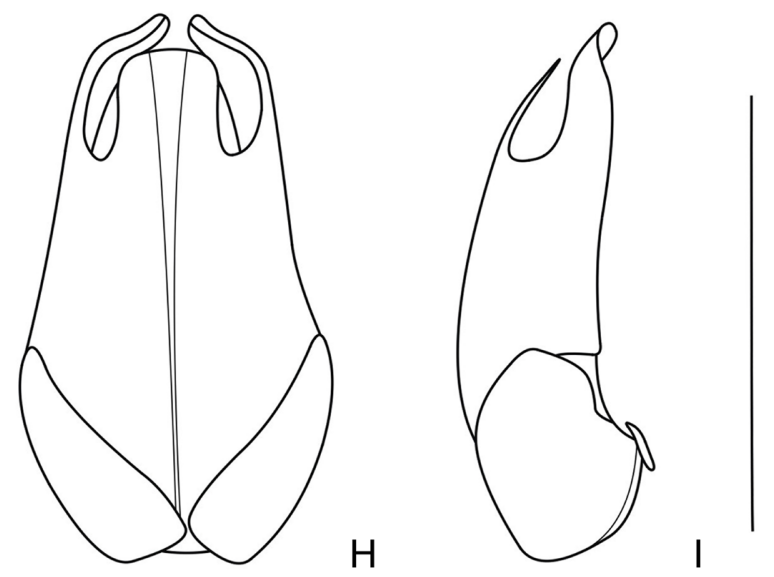

Fig. 1. Aedeagus (A, D, G: ventral view; B, E, H: dorsal view; C, F, I: lateral view). A-C. Fissocantharis bicoloriceps (Wittmer, 1995). D-F. F. denominata (Wittmer, 1997). G-I. F. fenchihuensis (Wittmer, 1982). Scale bars: $1.0 \mathrm{~mm}$. 
composed of a spiral tube which is slightly longer than diverticulum, provided with a thin accessory gland which is much shorter than the spiral tube of spermatheca; median oviduct situated in middle of vagina.

\section{Remarks}

In the original publication (Wittmer 1954), this species was only illustrated with male antennae. Here the genitalia of both sexes and abdominal sternite VIII of female are illustrated and described for the first time.

\section{Distribution}

Taiwan.

Fissocantharis fenchihuensis (Wittmer, 1982)

Figs $1 \mathrm{G}-\mathrm{I}, 2 \mathrm{~B}, 5 \mathrm{~B}$

Micropodabrus fenchihuensis Wittmer, 1982: 131, figs 18, 19, 29.

Fissocantharis fenchihuensis - Yang et al. 2012: 52.

\section{Material examined}

TAIWAN: Ilan Hsien: 1 ð, 1 \&, Yuanshan, 23 Mar. 2000, leg. H. Yoshitake; 1 ð, Yuanshan, 23-25 Mar. 2000, leg. T. Mizusawa; 1 đ̃, Yuanshan, Huxi vill., 4-16 Mar. 1999, leg. T. Mizusawa (all in KURA).

\section{Supplementary description}

AedeAGus (Fig. 1G-I). Ventral process of each paramere wide, distinctly narrowed apically, rounded at apex; conjoint dorsal plate of parameres developed, about two-thirds length of ventral process and as wide as half of the distance between outer margins of ventral processes, slightly widened apically, with straight apical margin.

Abdominal Sternite VIII of FEMALE (Fig. 5B). Distinctly protuberant in middle of posterior margin, the middle protuberance slightly and triangularly emarginate at apex, forming a pair of median lobe, which are slightly rounded at apices.

INTERNAL ORGAN OF REPRODUCTIVE SYSTEM (Fig. 2B). Vagina stout, abruptly thinned and extended into a slightly long duct at ventroapical portion; diverticulum and spermathecal duct arising from the end of the duct of vagina; diverticulum moderately long, spiral and slightly thinned apically; spermathecal duct distinctly shorter than and thicker than diverticulum; spermatheca composed of a spiral tube which is distinctly longer than diverticulum, provided with a thin accessory gland which is slightly shorter than the spiral tube of spermatheca; median oviduct situated in middle of vagina.

\section{Remarks}

In the original publication (Wittmer 1982), the species was illustrated with male antenna and aedeagus. Here, the aedeagus is illustrated again and described in detail, also the characters of abdominal sternite VIII and genitalia of female are provided for the first time.

\section{Distribution}

Taiwan. 


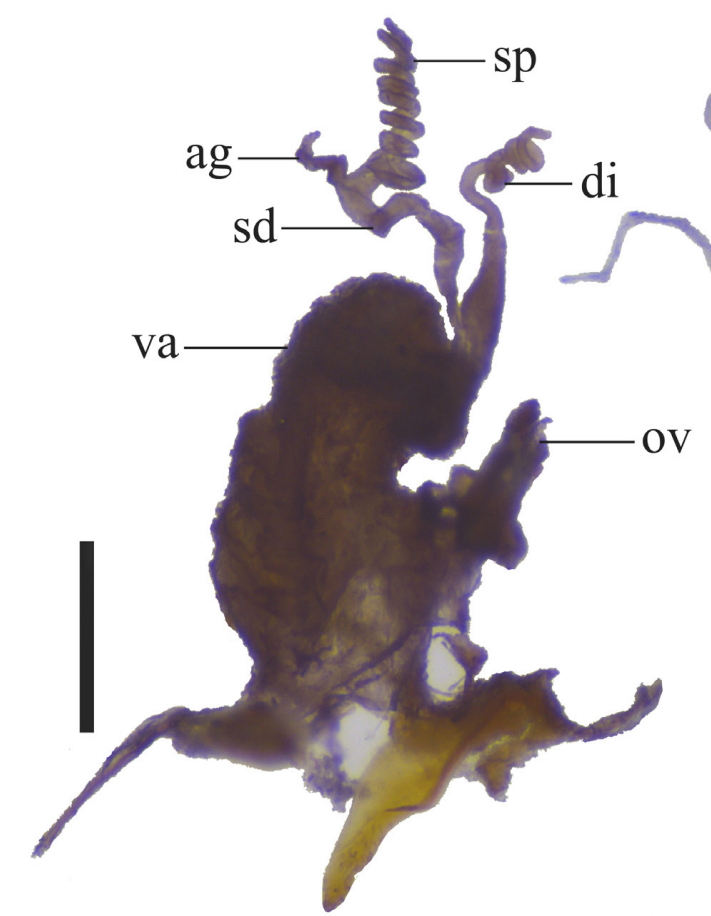

A

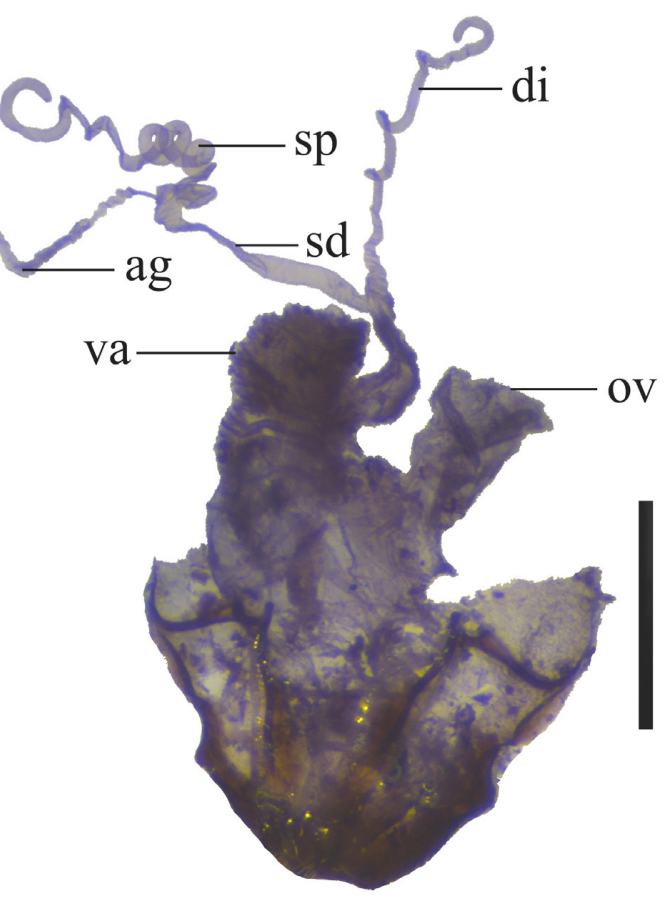

B

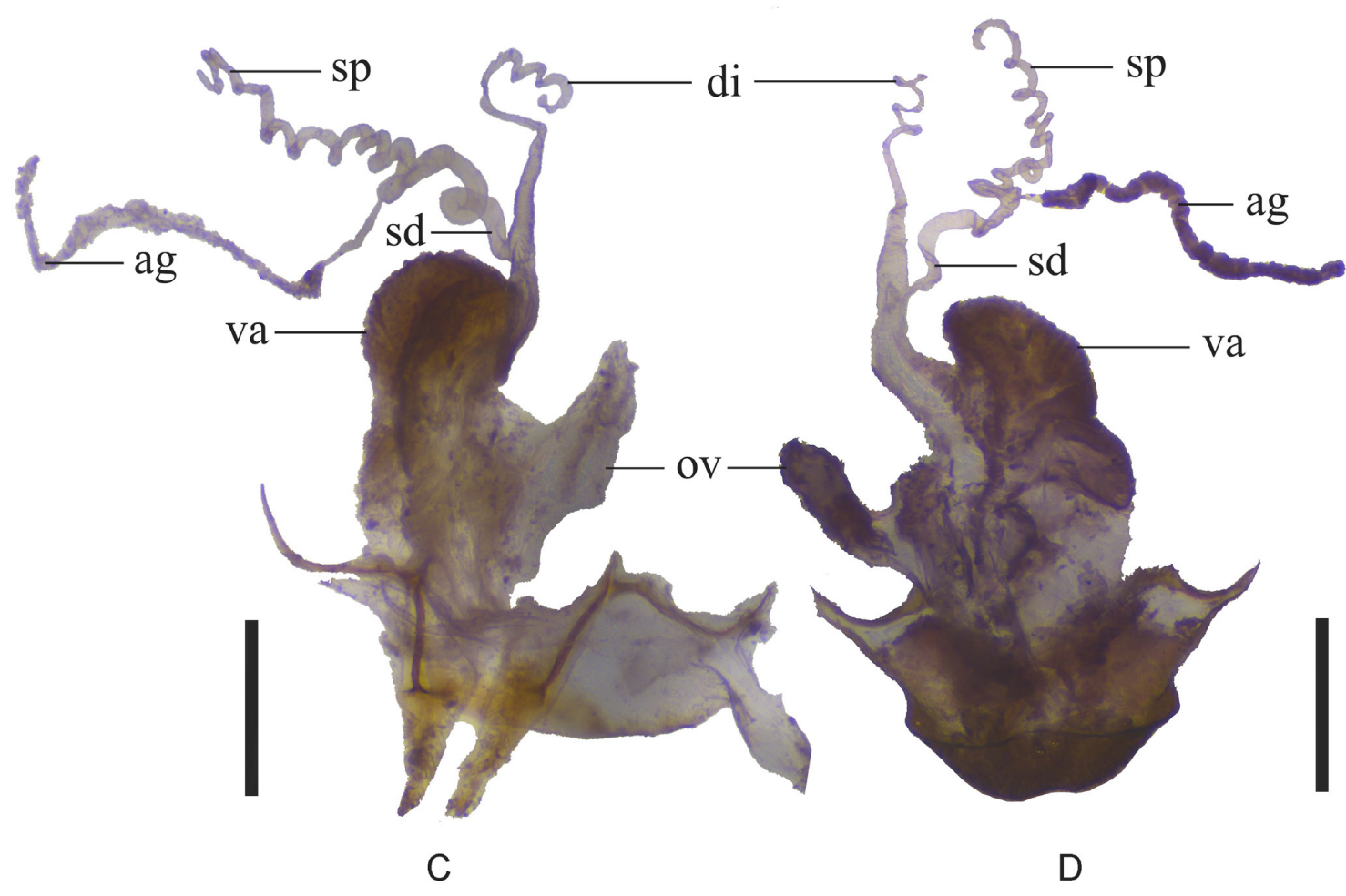

Fig. 2. Female genitalia, lateral view. A. Fissocantharis denominata (Wittmer, 1997). B. F. fenchihuensis (Wittmer, 1982). C. F. flavipennis Y. Yang, Okushima \& X. Yang, 2012. D. F. formosana (Pic, 1910). Scale bars: $0.5 \mathrm{~mm}$. 
Fissocantharis flavipennis Y. Yang, Okushima \& X. Yang, 2012

Figs $2 \mathrm{C}, 5 \mathrm{C}$

Fissocantharis flavipennis Y. Yang, Okushima \& X. Yang, 2012: 48, figs 5, 6, 9-11.

\section{Material examined}

TAIWAN: 1 (paratype), Nantou Hsien, Mt. Nengkaoshan, Yunhai, 22 Jun. 1989, leg. M. Satô (KURA).

\section{Supplementary description}

Abdominal Sternite VIII of FEMALE (Fig. 5C). Nearly straight at posterior margin.

INTERNAL ORGAN OF REPRODUCTIVE SYSTEM (Fig. 2C). Vagina stout, abruptly thinned and extended into a slightly long duct at ventroapical portion; diverticulum and spermathecal duct arising from the end of the duct of vagina; diverticulum moderately long, spiral and moderately thinned apically; spermathecal duct slightly shorter than diverticulum and nearly as thick as basal portion of diverticulum; spermatheca composed of a spiral tube which is slightly longer than diverticulum, provided with a thin accessory gland which is slightly longer than the spiral tube of spermatheca; median oviduct situated in middle of vagina.

\section{Remarks}

In the present study, the abdominal sternite VIII and genitalia of female are photographed and described for the first time.

\section{Distribution}

Taiwan.

Fissocantharis formosana (Pic, 1910)

Figs 2D, 3A-C, 5D

Rhagonycha formosana Pic, 1910: 271.

Podabrus curvatipes Pic, 1922: 4.

Rhagonycha obscurioripes Pic, 1926: 235.

Micropodabrus simplicicornis Wittmer, 1993: 209, figs 9, 12.

Micropodabrus formosanus - Wittmer, 1982: 129, figs 11-13.

Fissocantharis formosana - Yang et al. 2012: 47.

\section{Material examined}

TAIWAN: 1 đૈ, near Liu Kui, Shi Bao Shan, 3 May 1986, leg. K. Baba; 1 đ̊, 2 우, Liu Kui, 2 Apr. 1986, leg. K. Baba; 1 đ̃, 2 우, Ilan Hsien, Yuanshan, 23 Mar. 2000, leg. H. Youshitake; 1 đ, same locality as the former, 23-25 Mar. 2000, leg. T. Mizusawa (all in KURA).

\section{Supplementary description}

AedeAgus (Fig. 3A-C). Ventral process of each paramere wide, slightly narrowed apically, largely hooked at apex; conjoint dorsal plate of parameres moderately developed, about half length of ventral process and as wide as half of the distance between outer margins of ventral processes, moderately narrowed apically, with straight apical margin. 

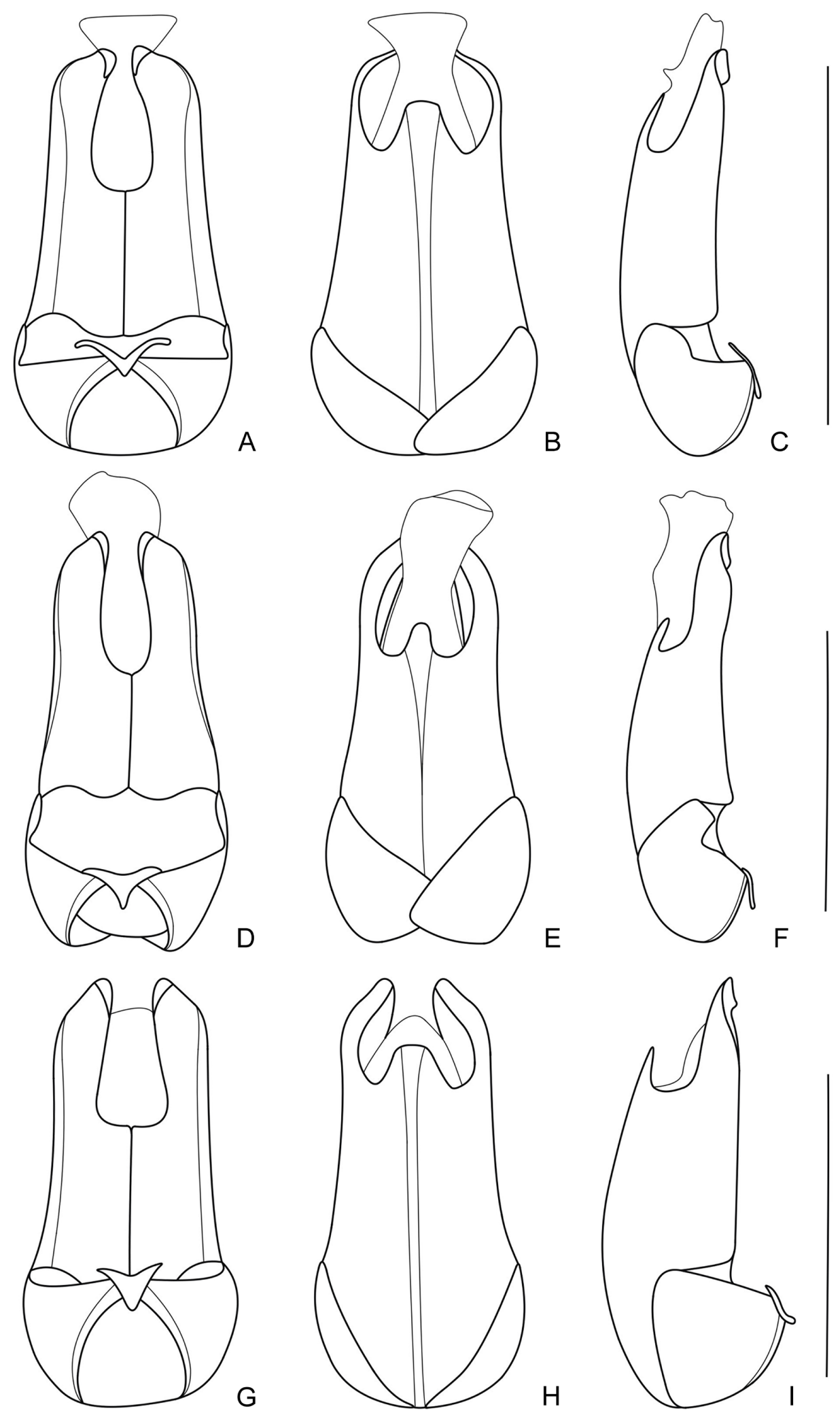

Fig. 3. Aedeagus (A, D, G: ventral view; B, E, H: dorsal view; C, F, I: lateral view). A-C. Fissocantharis formosana (Pic, 1910). D-F. F. gressitti (Wittmer, 1954). G-I. F. kurosawai (Wittmer, 1982). Scale bars: $1.0 \mathrm{~mm}$. 
ABdominal STERNITE VIII OF FEMALE (Fig. 5D). Slightly protuberant in middle of posterior margin, the middle protuberance widely and shallowly emarginate at apex, forming a pair of median lobes, which are slightly arcuate at apices.

INTERNAL ORGAN OF REPRODUCTIVE SYSTEM (Fig. 2D). Vagina stout, abruptly thinned and extended into a slightly long duct at ventroapical portion; diverticulum and spermathecal duct arising from the end of the duct of vagina; diverticulum moderately long, spiral and distinctly thinned apically; spermathecal duct distinctly shorter than diverticulum and narrower than basal portion of diverticulum; spermatheca composed of a spiral tube which is nearly as long as diverticulum, provided with a thin accessory gland which is slightly shorter than the spiral tube of spermatheca; median oviduct situated in middle of vagina.

\section{Remarks}

The aedeagus of this species was illustrated in ventral and dorsal views by Wittmer (1982), here it is illustrated again and described in detail. Also, the characters of abdominal sternite VIII and genitalia of female are provided for the first time.

\section{Distribution}

Taiwan.

Fissocantharis gressitti (Wittmer, 1954)

Figs 3D-F, 4A, 5E

Podabrus gressitti Wittmer, 1954: 272, fig. 1.

Micropodabrus gressitti - Wittmer 1982: 132.

Fissocantharis gressitti - Yang et al. 2012: 52.

\section{Material examined}

TAIWAN: Nantou Hsien: 1 \&, Wanda, 8 May 1997, leg. C. Lou; 1 \&, Yu Shih, 1900 m, 4 Jul. 1986, leg. K. Baba; 1 + , Nr. Sungkang, Meifeng, 13 May 1994, leg. T. Kishimoto; 1 ð, same data, 12 May 1994; 4 우, Hohuanshi, 30 Apr. 1994, leg. T. Kishimoto \& T. Shimizu; Kao Hsiung Hsien: 1 đૈ, MeishanTinchi, 800-2300 m, 29 Jun. 1986, leg. K. Baba (all in KURA).

\section{Supplementary description}

AEDEAGus (Fig. 3D-F). Ventral process of each paramere wide, slightly narrowed apically, slightly hooked at apex; conjoint dorsal plate of parameres slightly reduced, about one fourth length of ventral process and as wide as one-fourth of the distance between outer margins of ventral processes, slightly narrowed apically, with slightly rounded apical margin.

ABDOMINAL STERNITE VIII of FEMALE (Fig. 5E). Distinctly protuberant in middle of posterior margin, the middle protuberance distinctly and roundly emarginate at apex, forming a pair of median lobes, which are narrowly rounded at apices.

INTERNAL ORGAN OF REPRODUCTIVE SYSTEM (Fig. 4A). Vagina stout, abruptly thinned and extended into a slightly long duct at ventroapical portion; diverticulum and spermathecal duct arising from the end of the duct of vagina; diverticulum moderately long, spiral and distinctly thinned apically; spermathecal duct slightly longer than diverticulum and distinctly thinner than basal portion of diverticulum; spermatheca composed of a spiral tube which is nearly as long as diverticulum, provided with a thin accessory gland 
which is slightly shorter than the spiral tube of spermatheca; median oviduct situated in middle of vagina.

\section{Remarks}

In the original publication (Wittmer 1954), this species was only illustrated with male antennae. Here the genitalia of both sexes and abdominal sternite VIII of female are illustrated and described for the first time.

\section{Distribution}

Taiwan.

Fissocantharis kurosawai (Wittmer, 1982)

Figs 3G-I, 4B, 5F

Micropodabrus kurosawai Wittmer, 1982: 132, figs 20, 30.

Fissocantharis kurosawai - Yang et al. 2012: 52.

\section{Material examined}

TAIWAN: 1 ${ }^{\lambda}$, near Liu Kui, Shi Nan Shan, 4 May 1986, leg. K. Baba; 1 q, near Liu Kui, Shyk Shan, 25 Apr. 1986, leg. K. Baba (both in KURA).

\section{Supplementary description}

Aedeagus (Fig. 3G-I). Ventral process of each paramere slightly wide, slightly narrowed apically, slightly hooked at apex; conjoint dorsal plate of parameres moderately developed, about half length of ventral process and as wide as half of the distance between outer margins of ventral processes, moderately narrowed apically, with straight apical margin.

AbDominal STERNite VIII of FEMALE (Fig. 5F). Distinctly protuberant in middle of posterior margin, the middle protuberance moderately and triangularly emarginate at apex, forming a pair of median lobes, which are widely rounded at apices.

INTERNAL ORGAN OF REPRODUCTIVE SYSTEM (Fig. 4B). Vagina stout, abruptly thinned and extended into a slightly long duct at ventroapical portion; diverticulum and spermathecal duct arising from the end of the duct of vagina; diverticulum moderately long, spiral and moderately thinned apically; spermathecal duct distinctly shorter than diverticulum and thinner than basal portion of diverticulum; spermatheca composed of a spiral tube which is slightly longer than diverticulum, provided with a thin accessory gland which is distinctly shorter than the spiral tube of spermatheca; median oviduct situated in middle of vagina.

\section{Remarks}

In the original publication (Wittmer 1982), the aedeagus was illustrated in dorsal view, here it is illustrated in ventral, dorsal and lateral views and described in detail. Its abdominal sternite VIII and genitalia of female are illustrated and described for the first time.

\section{Distribution}

Taiwan. 

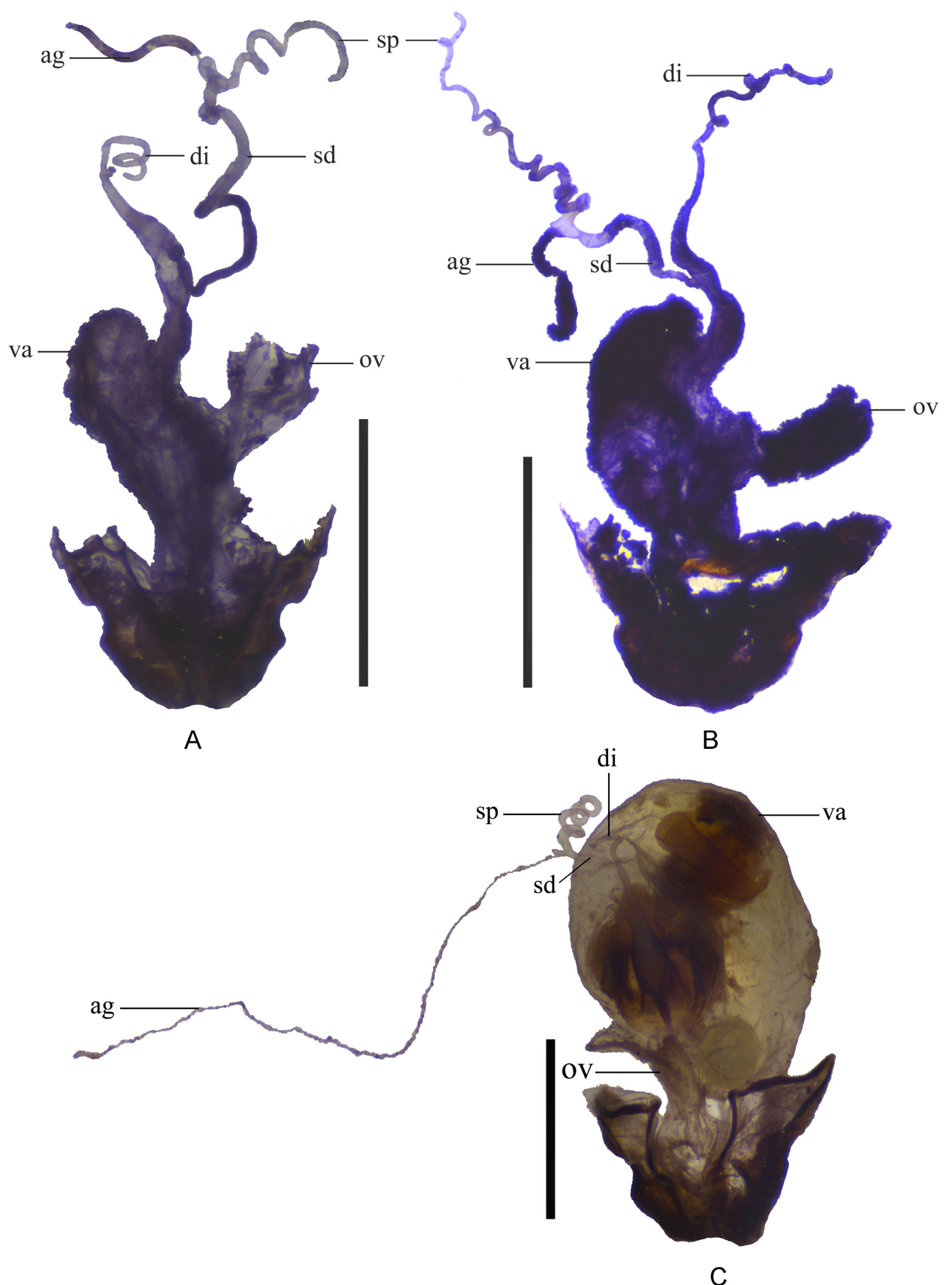

Fig. 4. Female genitalia, lateral view. A. Fissocantharis gressitti (Wittmer, 1954). B. F. kurosawai (Wittmer, 1982). C. F. laticornis Y. Yang, Okushima \& X. Yang, 2012. Scale bars: $1.0 \mathrm{~mm}$. 


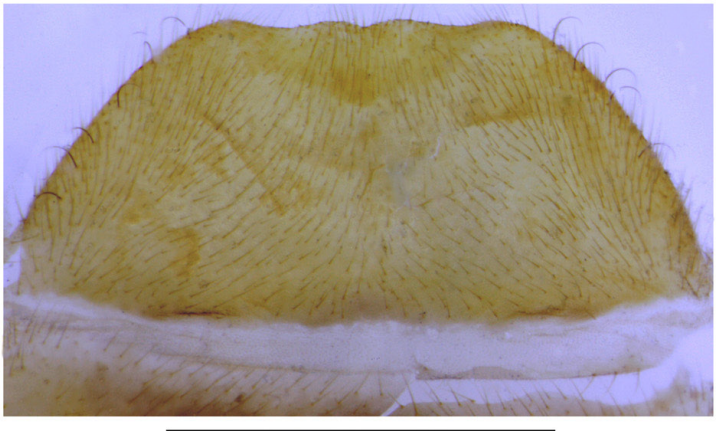

A

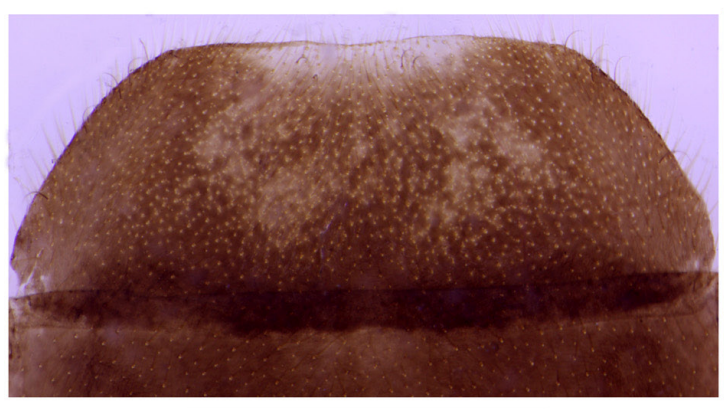

C

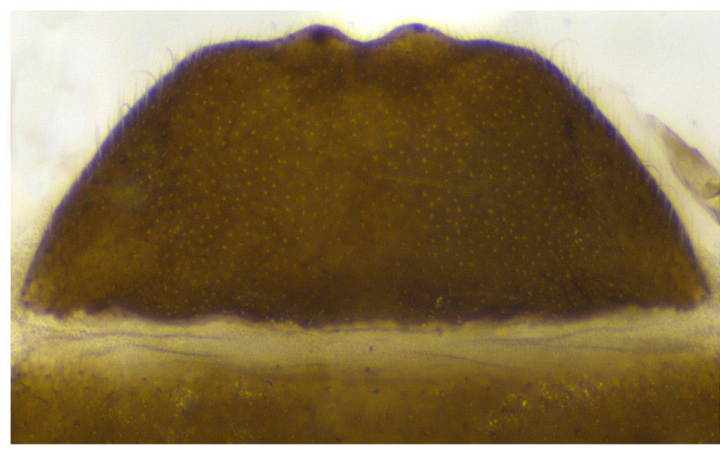

E

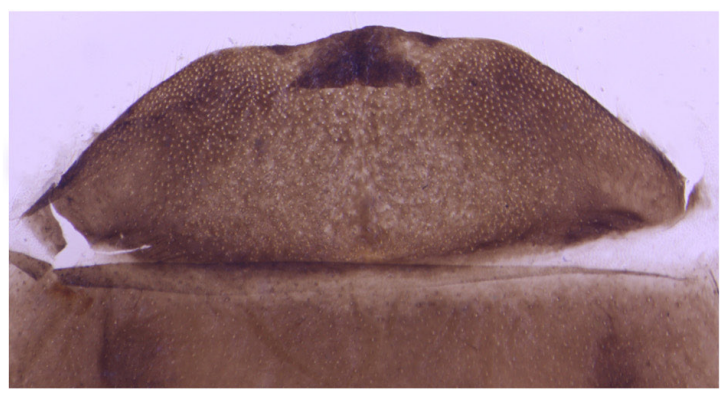

G

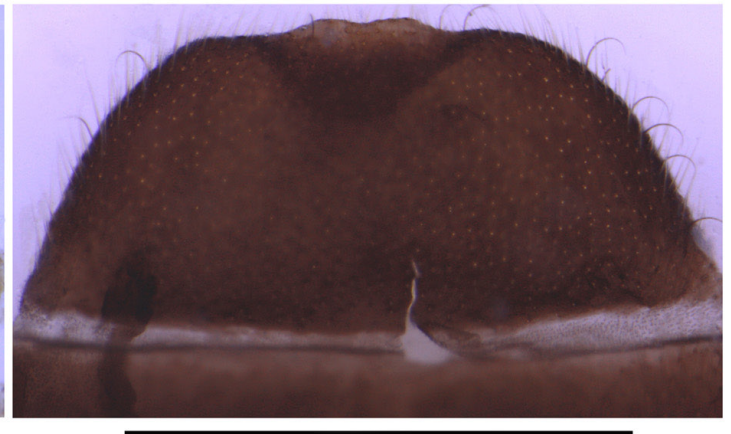

B

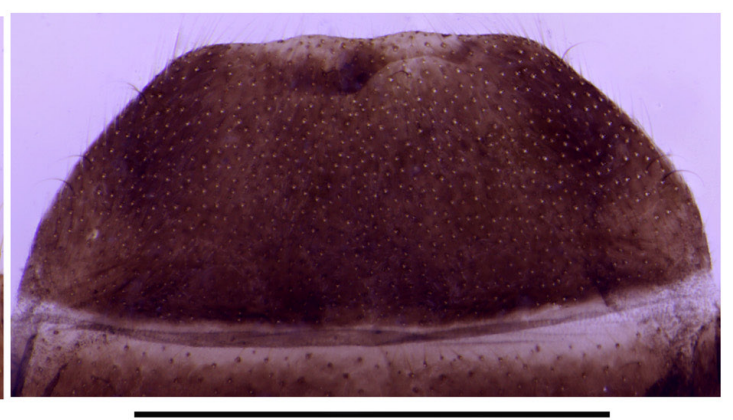

D

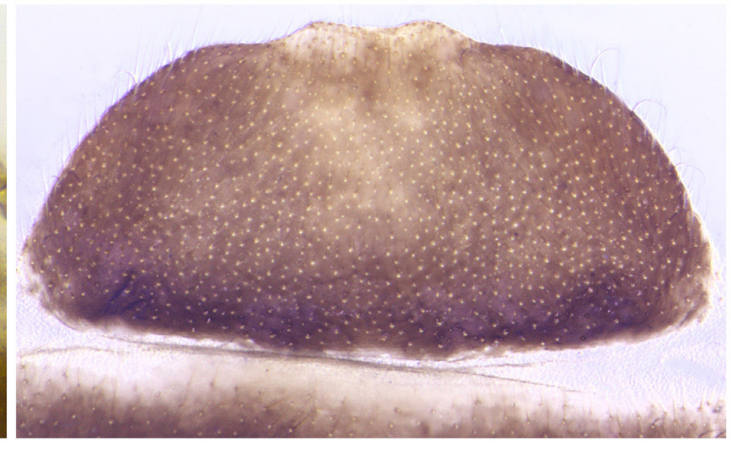

$\mathrm{F}$

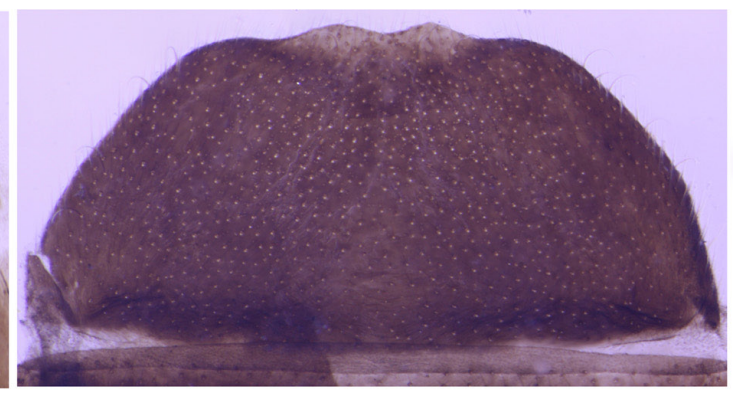

$\mathrm{H}$

Fig. 5. Abdominal sternite VIII of female, ventral view. A. Fissocantharis denominata (Wittmer, 1997). B. F. fenchihuensis (Wittmer, 1982). C. F. flavipennis Yang, Okushima \& Yang, 2012. D. F. formosana (Pic, 1910). E. F. gressitti (Wittmer, 1954). F. F. kurosawai (Wittmer, 1982). G. F. laticornis Y. Yang, Okushima \& X. Yang, 2012. H. F. lishanensis (Wittmer, 1982). Scale bars: $1.0 \mathrm{~mm}$. 
Fissocantharis laticornis Y. Yang, Okushima \& X. Yang, 2012

Figs $4 \mathrm{C}, 5 \mathrm{G}$

Fissocantharis laticornis Y. Yang, Okushima \& X. Yang, 2012: 51, figs 7, 8 12-14.

\section{Material examined}

TAIWAN: 1 (paratype), Taoyuan Hsien, Daguanshan, 4 Apr. 1991, leg. Y. Okushima (KURA).

\section{Supplementary description}

ABdOMinal STERNITE VIII of FEMALE (Fig. 5G). Distinctly protuberant in middle of posterior margin, the middle protuberance widely subtriangular at apex.

INTERNAL ORGAN OF REPRODUCTIVE SYSTEM (Fig. 4C). Vagina stout and nearly global, abruptly narrowed and extended into a moderately long duct near middle of ventral side, the duct distinctly narrowed apically; diverticulum and spermathecal duct arising from the end of the duct of vagina; diverticulum short, spiral and thin; spermathecal duct nearly as long as and slightly thicker than diverticulum; spermatheca composed of a spiral tube which is distinctly longer than diverticulum, basal portion extended into a short tube, where the accessory gland opening; accessory gland thin and very long, much longer than the spiral tube of spermatheca; median oviduct situated at base of vagina.

\section{Remarks}

In the present study, the abdominal sternite VIII and genitalia of female are photographed and described for the first time.

\section{Distribution}

Taiwan.

Fissocantharis lishanensis (Wittmer, 1982)

Figs $5 \mathrm{H}, 6 \mathrm{~A}-\mathrm{C}, 8 \mathrm{~A}$

Micropodabrus lishanensis Wittmer, 1982: 131, figs 17, 28.

Fissocantharis lishanensis - Yang et al. 2012: 52.

\section{Material examined}

TAIWAN: Taoyuan Hsien: $2 \hat{\jmath} \widehat{\partial}$, Ssuleng, 1300 m, 23 Mar. 1991, leg. A. Shinohara; 1 + , Ssuleng, 12 Apr. 1991, leg. K. La; 1 đ’, Nr. Sungkang, Mei Fon, 12 May 1994, leg. T. Kishimoto; 1 q, Tsuifeng, 18 Jun. 1989, leg. M. Satô; 1 q, Mt. Kuantao, 24 Apr. 1984, leg. Y. Kusakabe; 3 $q$, Nanshanchi, 31 Mar. 1996, leg. R. Matsumoto; 1 , Baling, 5-8 Apr. 1991, leg. T. Kishimoto; 1 q, nr. Mt. Lalashan, 5 May 1983, leg. M. Hasegawa; Ilan Hsien: 1 Õ, Nanshan, 23 Jul. 1995, leg. C. Lou; Taichung Hsien: 1 đ̄, Tashüehshan Mts, Anmashan, 2230 m, 15 Jun. 1989, leg. M. Satô; 1 q, same data, 14 Jun. 1989; 1 q, Anmashan, 2200 m, 29 Jul. 1997, leg. Y. Arita; 1 q, Kukuan, 18 Apr. 1986, leg. G. Ito (all in KURA).

\section{Supplementary description}

AEDEAGus (Fig. 6A-C). Ventral process of each paramere wide, slightly narrowed apically, moderately hooked at apex; conjoint dorsal plate of parameres slightly reduced, about half length of ventral process and as wide as one-third of the distance between outer margins of ventral processes, slightly narrowed apically, with straight apical margin. 

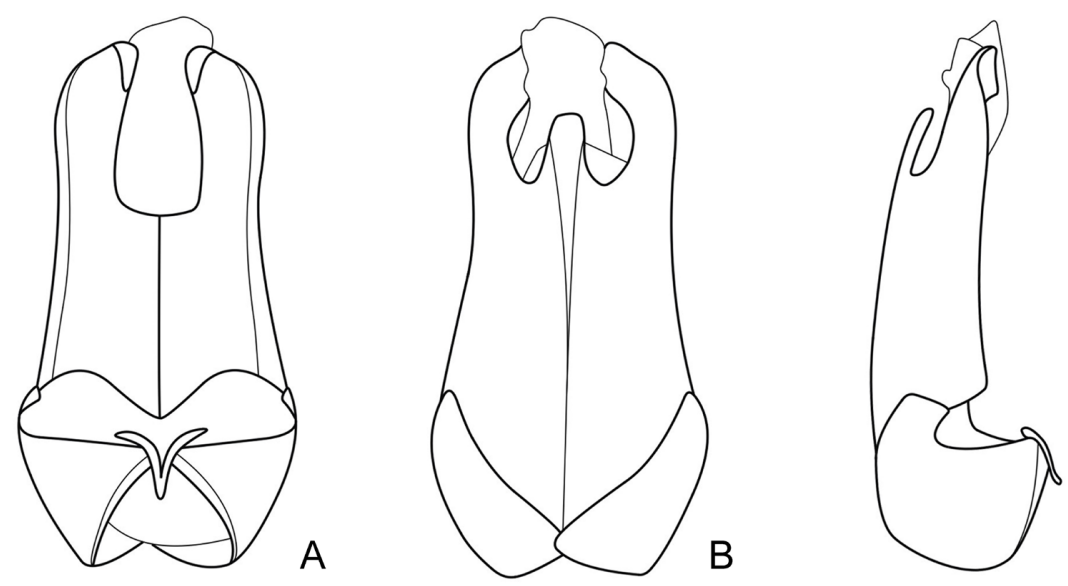

C
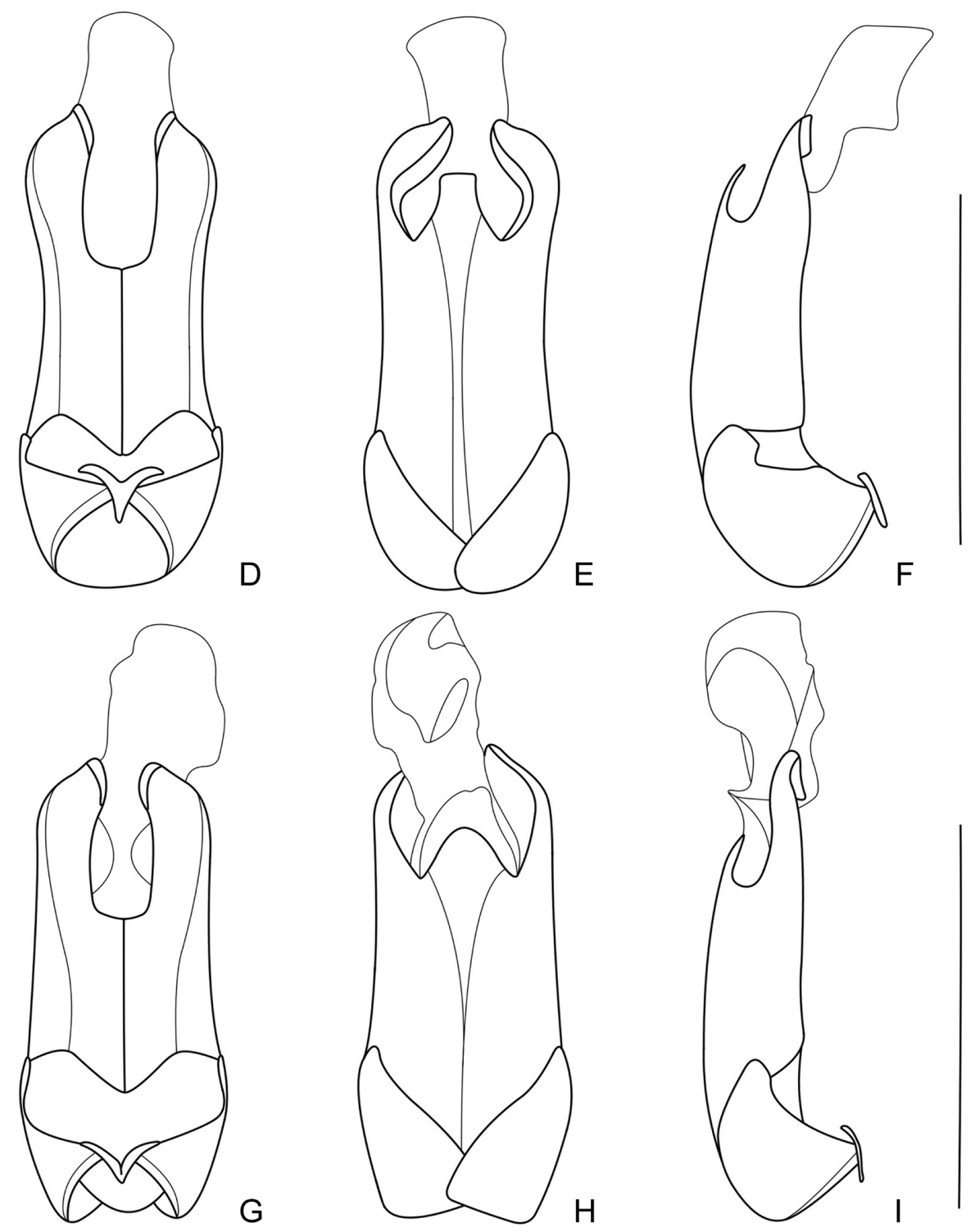

Fig. 6. Aedeagus (A, D, G: ventral view; B, E, H: dorsal view; C, F, I: lateral view). A-C. Fissocantharis lishanensis (Wittmer, 1982). D-F. F. nantouensis (Wittmer, 1995). G-I. F. nigriceps Y. Yang \& Okushima sp. nov. Scale bars: $1.0 \mathrm{~mm}$. 
Abdominal Sternite VIII of Female (Fig. 5H). Distinctly protuberant in middle of posterior margin, the middle protuberance moderately and triangularly emarginate at apex, forming a pair of median lobes, which are widely subrounded at apices.

INTERNAL ORGAN OF REPRODUCTIVE SYSTEM (Fig. 8A). Vagina stout, abruptly thinned and extended into a slightly long duct at ventroapical portion; diverticulum and spermathecal duct arising from the end of the duct of vagina; diverticulum moderately long, spiral and distinctly thinned apically; spermathecal duct distinctly shorter than diverticulum and thinner than basal portion of diverticulum; spermatheca composed of a spiral tube which is distinctly longer than diverticulum, provided with a thin accessory gland which is slightly shorter than the spiral tube of spermatheca; median oviduct situated in middle of vagina.

\section{Remarks}

In the original publication (Wittmer 1982), the aedeagus was illustrated in dorsal view, here it is illustrated in ventral, dorsal and lateral views and described in detail. Its abdominal sternite VIII and genitalia of female are illustrated and described for the first time.

\section{Distribution}

Taiwan.

Fissocantharis nantouensis (Wittmer, 1995)

Figs $6 \mathrm{D}-\mathrm{F}, 8 \mathrm{~B}, 11 \mathrm{~A}$

Micropodabrus nantouensis Wittmer, 1995: 113, figs 3, 4.

Fissocantharis nantouensis - Yang et al. 2012: 52.

\section{Material examined}

TAIWAN: Nantou Hsien: 1 q, Meixi, 10 Apr. 1991, leg. T. Kishimoto; 1 đ̂, Mt. Howanshan, 17 Mar. 1991, leg. C.-C. Lo; 1 J, Sungkang, 26 Apr. 1977, leg. S. Saito (all in KURA).

\section{Supplementary description}

AEDEAGus (Fig. 6D-F). Ventral process of each paramere wide, slightly narrowed apically, moderately hooked at apex; conjoint dorsal plate of parameres moderately developed, about half length of ventral processes and as wide as half of the distance between outer margins of ventral processes, distinctly narrowed apically, with straight apical margin.

ABDOMINAL STERNITE VIII OF FEMALE (Fig. 11A). Distinctly protuberant in middle of posterior margin, the middle protuberance moderately and triangularly emarginate at apex, forming a pair of median lobes, which are widely triangular at apices.

INTERNAL ORGAN OF REPRODUCTIVE SYSTEM (Fig. 8B). Vagina stout, abruptly thinned and extended into a slightly long duct at ventroapical portion; diverticulum and spermathecal duct arising from the end of the duct of vagina; diverticulum moderately long, spiral and distinctly thinned apically; spermathecal duct distinctly shorter than diverticulum and thinner than basal portion of diverticulum; spermatheca composed of a spiral tube which is slightly longer than diverticulum, provided with a thin accessory gland which is slightly shorter than the spiral tube of spermatheca; median oviduct situated in middle of vagina. 


\title{
Remarks
}

In the original publication (Wittmer 1995), this species was only illustrated with male antennae. Here the genitalia of both sexes and abdominal sternite VIII of female are illustrated and described for the first time.

\section{Distribution}

Taiwan.

Fissocantharis nigriceps Y. Yang \& Okushima sp. nov. urn:1sid:zoobank.org:act:B6F2406E-AC8F-4004-A468-A1602747E266

Figs 6G-I, 12A

\section{Diagnosis}

This species is similar to F. formosana (Pic, 1910), but can be differentiated from the latter by the black head, eyes strongly protruding, pronotum distinctly widened posteriorly, aedeagus: conjoint dorsal plate of parameres with round apical margin. It also resembles F. minor (Wittmer, 1997) in the body coloration, but differs in the following characters: eyes strongly protruding, pronotum slightly longer than wide, aedeagus: conjoint dorsal plate of parameres about half length of ventral process, while in the latter species, eyes moderately protruding, pronotum nearly as long as wide, aedeagus: conjoint dorsal plate of parameres as long as ventral process.

\section{Etymology}

The specific epithet is derived from the Latin niger (black) and ceps (head), referring to its black head.

\section{Type material}

\section{Holotype}

TAIWAN: §̊, Taoyuan Hsien, Hsileng, 27 Apr. 1978, leg. S. Saito (NMNS).

\section{Description}

\author{
Male (Fig. 12A)
}

Body length: $7.0 \mathrm{~mm}$; width: $1.5 \mathrm{~mm}$.

BoDy. Black, prothorax and legs orange, tarsi black. Body densely covered with recumbent gray pubescence.

HeAD. Subquadrate, temples distinctly narrowed posteriorly, surface densely and finely punctate; eyes strongly protruding, head width across eyes distinctly wider than anterior margin of pronotum; terminal maxillary palpomeres subtriangular, widest nearly in middle, acurate on apical parts of inner margins, acute at apices; antennae filiform and simple, extending to basal two-length of elytra, antennomeres II slightly longer than wide, III about twice as long as II, IV slightly longer than III, XI slightly longer than $\mathrm{X}$, pointed at apices.

Pronotum. Subquadrate, slightly longer than wide, distinctly widened posteriorly, anterior margin rounded, lateral margins slightly sinuate, posterior margin narrowly bordered and arcuate, anterior angles rounded, posterior angles nearly rectangular; disc distinctly convex on posterolateral parts, surface semilustrous, sparsely and finely punctate.

ELYTRA. About 3.5 times as long as humeral width, 5.0 times longer than pronotum, nearly parallelsided, disc densely and coarsely punctate. 

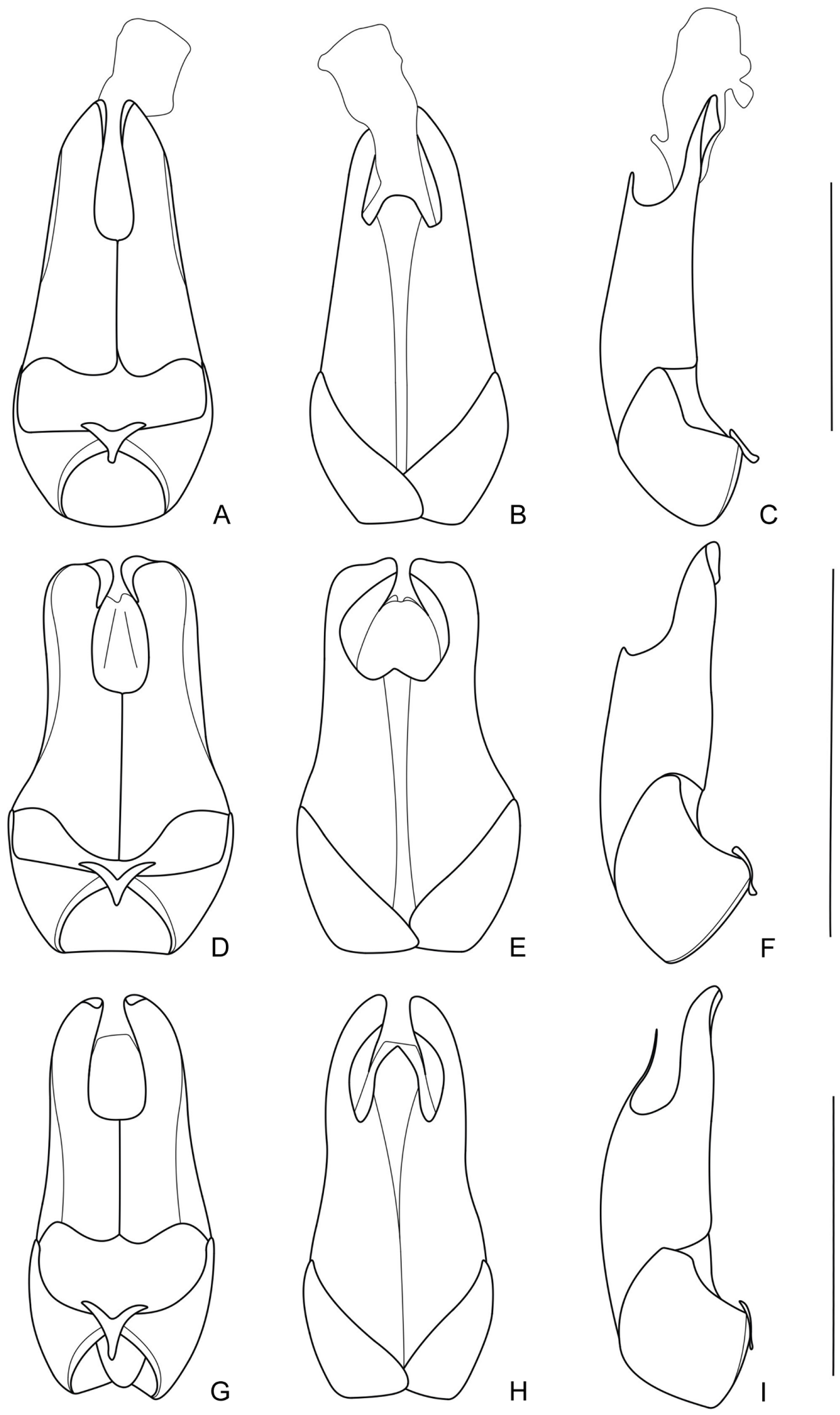

Fig. 7. Aedeagus (A, D, G: ventral view; B, E, H: dorsal view; C, F, I: lateral view). A-C. Fissocantharis piluchiensis (Wittmer, 1995). D-F. F. pingtungensis (Wittmer, 1982). G-I. F. ssulingensis (Wittmer, 1995). Scale bars: $1.0 \mathrm{~mm}$. 
LEGs. With all tarsal claws bifid, upper claws nearly as long as lower ones.

AEDEAGus (Fig. 6G-I). Ventral process of each paramere wide, slightly narrowed apically, moderately hooked at apex; conjoint dorsal plate of parameres moderately developed, about half length of ventral process and as wide as half of the distance between outer margins of ventral processes, distinctly narrowed apically, with round apical margin.

\section{Female}

Unknown.

\section{Distribution}

Taiwan.

Fissocantharis piluchiensis (Wittmer, 1995)

Figs $7 \mathrm{~A}-\mathrm{C}, 8 \mathrm{C}, 11 \mathrm{~B}$

Micropodabrus piluchiensis Wittmer, 1995: 114, figs 5, 6.

Fissocantharis piluchiensis - Yang et al. 2012: 52.

\section{Material examined}

TAIWAN: Taichung Hsien: 1 đ̃, Tashüehshan Mts, Anmashan, 2230 m, 15 Jun. 1989, leg. M. Satô; 2 우, same data, 14 Jun. 1989; 1 + , Wuling, 27 Jun. 1989, leg. M. Satô; 3 우, Anmashan, 16 Jun. 1989, leg. M. Owada; 1 ㅇ, same locality and date, leg. M. Satô; 1 đ̆, Kaohsiung Hsien, Taoyuan, Hsiu Lake, 2 May 1996, leg. Y. Y. Lien; Nantou Hsien: 1 q, Yuankang, 24 Jun. 1989, leg. S. Uéno; 1 \&, Piluchi, 26 Jun. 1989, leg. M. Satô (all in KURA).

\section{Supplementary description}

AEDEAGUS (Fig. 7A-C). Ventral process of each paramere wide, distinctly narrowed apically, moderately hooked at apex; conjoint dorsal plate of parameres slightly developed, about one-fourth length of ventral process and as wide as half of the distance between outer margins of ventral processes, moderately narrowed apically, with slightly rounded apical margin.

ABDOMINAL STERNITE VIII of FEMALE (Fig. 11B). Moderately protuberant in middle of posterior margin, the middle protuberance moderately and widely triangularly emarginate at apex, forming a pair of median lobes, which are subtriangular at apices.

INTERNAL ORGAN OF REPRODUCTIVE SYSTEM (Fig. 8C). Vagina stout, slightly thinned and extended into a slightly long duct at ventroapical portion; diverticulum and spermathecal duct arising from the end of the duct of vagina; diverticulum moderately long, spiral and abruptly narrowed apically; spermathecal duct distinctly shorter than diverticulum and thinner than basal portion of diverticulum; spermatheca composed of a spiral tube which is slightly longer than diverticulum, provided with a thin accessory gland which is slightly shorter than the spiral tube of spermatheca; median oviduct situated in middle of vagina.

\section{Remarks}

In the original publication (Wittmer 1995), this species was only illustrated with male antennae. Here the genitalia of both sexes and abdominal sternite VIII of female are illustrated and described for the first time. 

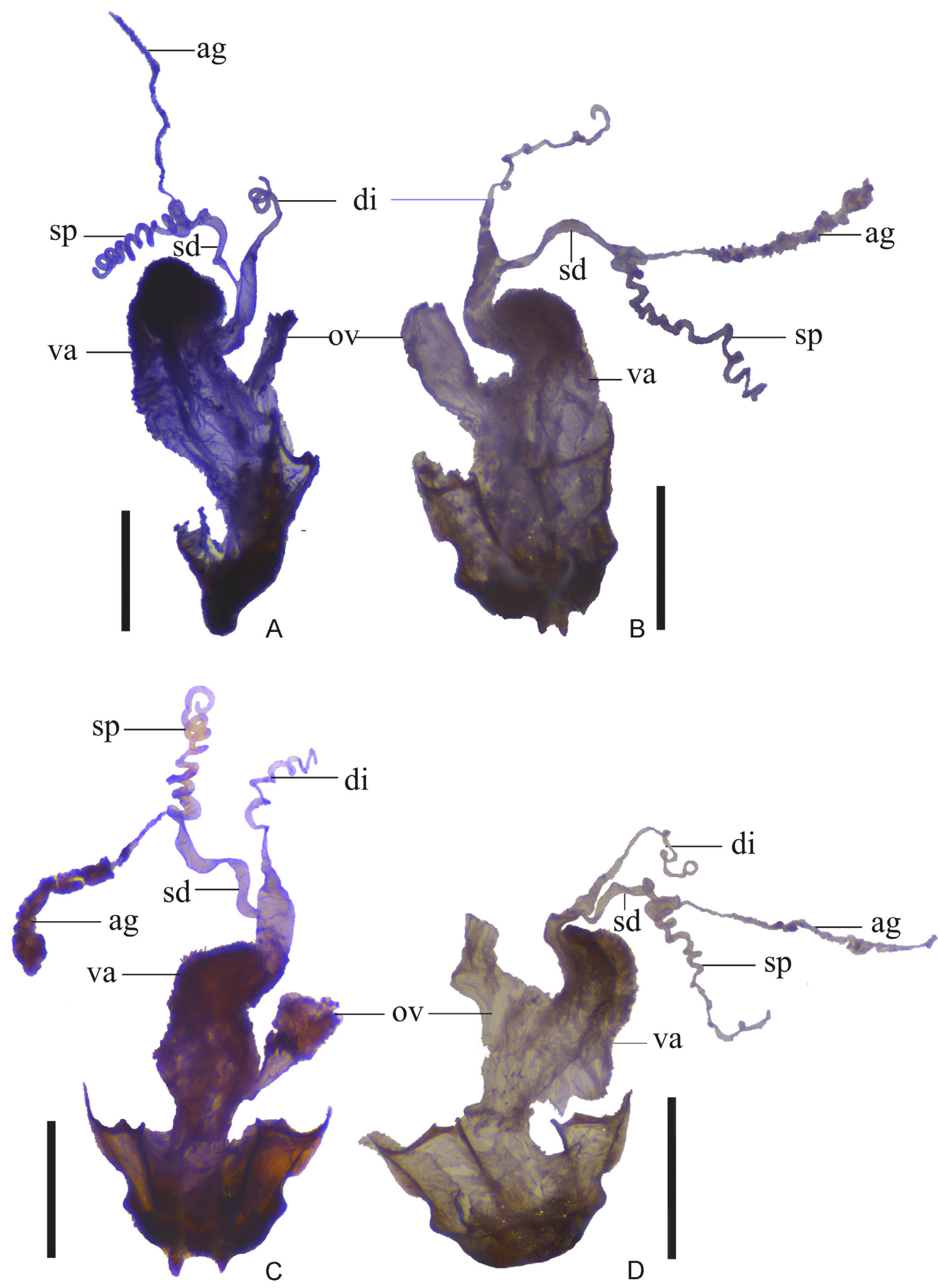

Fig. 8. Female genitalia, lateral view. A. Fissocantharis lishanensis (Wittmer, 1982). B. F. nantouensis (Wittmer, 1995). C. F. piluchiensis (Wittmer, 1995). D. F. pingtungensis (Wittmer, 1982). Scale bars: $0.5 \mathrm{~mm}$. 


\section{Distribution}

Taiwan.

Fissocantharis pingtungensis (Wittmer, 1982)

Figs 7D-F, 8D, 11C

Micropodabrus pingtungensis Wittmer, 1982: 129, figs 14, 15, 26.

Fissocantharis pingtungensis - Yang et al. 2012: 52.

\section{Material examined}

TAIWAN: 3 ððð, 2 우, Liu Kui, 2 Apr. 1986, leg. K. Baba (all in KURA).

\section{Supplementary description}

AEDEAGus (Fig. 7D-F). Ventral process of each paramere wide, slightly narrowed apically, moderately hooked at apex; conjoint dorsal plate of parameres strongly reduced, slightly triangularly protuberant in middle of apical margin.

Abdominal Sternite VIII of FeMALe (Fig. 11C). Distinctly and triangularly emarginate in middle of posterior margin.

INTERNAL ORGAN OF REPRODUCTIVE SYSTEM (Fig. 8D). Vagina stout, abruptly thinned and extended into a slightly long duct at ventroapical portion; diverticulum and spermathecal duct arising from the end of the duct of vagina; diverticulum moderately long, spiral and moderately thinned apically; spermathecal duct slightly shorter than diverticulum and thinner than basal portion of diverticulum; spermatheca composed of a spiral tube which is slightly longer than diverticulum, provided with a thin accessory gland which is nearly as long as the spiral tube of spermatheca; median oviduct situated in middle of vagina.

\section{Remarks}

In the original publication (Wittmer 1982), the aedeagus of species was illustrated in ventral and dorsal views, here it is illustrated again and also in lateral view. Here the genitalia and abdominal sternite VIII of female are illustrated and described for the first time.

\section{Distribution}

Taiwan.

\section{Fissocantharis ssulingensis (Wittmer, 1995)}

Figs 7G-I, 10A, 11D

Micropodabrus ssulingensis Wittmer, 1995: 116, fig. 7.

Fissocantharis ssulingensis - Yang et al. 2012: 52.

\section{Material examined}

TAIWAN: 1 đ, Taoyuan Hsien, Mt. Lalashan, 4 Apr. 1991, leg. T. Kishimoto; 1 , , Nantou Hsien, Meimu-Holuan, 30 Mar. 1998, leg. F. Hayashi (both in KURA). 


\section{Supplementary description}

AedEaGus (Fig. 7G-I). Ventral process of each paramere wide, slightly narrowed apically, slightly hooked at apex; conjoint dorsal plate of parameres moderately developed, about two-thirds length of ventral process and as wide as half of the distance between outer margins of ventral processes, slightly narrowed apically at basal portion and distinctly narrowed at apical portion, with apical margin acute in middle.

AbDOMINAL STERNITE VIII OF FEMALE (Fig. 11D). Distinctly protuberant in middle of posterior margin, the middle protuberance distinctly and triangularly emarginate at apex, forming a pair of median lobes, which are triangular at apices.

INTERNAL ORGAN OF REPRODUCTIVE SYSTEM (Fig. 10A). Vagina stout, abruptly thinned and extended into a slightly long duct at ventroapical portion; diverticulum and spermathecal duct arising from the end of the duct of vagina; diverticulum moderately long, spiral and moderately thinned apically; spermathecal duct distinctly shorter than diverticulum and thinner than basal portion of diverticulum; spermatheca composed of a spiral tube which is nearly as long as diverticulum, basal portion extended into a short tube, where an accessory gland opening; the accessory gland thin and nearly as long as the spiral tube of spermatheca; median oviduct situated in middle of vagina.

\section{Remarks}

In the original publication (Wittmer 1995), this species was only illustrated with male antennae. Here the genitalia of both sexes and abdominal sternite VIII of female are illustrated and described for the first time.

\section{Distribution}

Taiwan.

Fissocantharis taipeiana (Wittmer, 1982)

Figs 9A-C, 10B, 11E

Micropodabrus taipeianus Wittmer, 1982: 134, figs 23, 24, 32.

Fissocantharis taipeiana - Yang et al. 2012: 52.

\section{Material examined}

TAIWAN: 1 ô, 1 q, Taipei Hsien, Wulai, Fushan-Hsihhsien, 19 Apr. 1996, leg. Y.Y. Lien; 1 ô, Shi Nan Shan, near Liu Kui, 4 May 1986, leg. K. Baba (all in KURA).

\section{Supplementary description}

AEDEAGus (Fig. 9A-C). Ventral process of each paramere wide, distinctly narrowed at apical portion, moderately hooked at apex; conjoint dorsal plate of parameres slightly developed, about one-third length of ventral process and as wide as one-third of the distance between outer margins of ventral processes, slightly narrowed apically, with nearly straight apical margin.

AbDOMinal STERnite VIII of FeMALE (Fig. 11E). Nearly straight at posterior margin.

INTERNAL ORGAN OF REPRODUCTIVE SYSTEM (Fig. 10B). Vagina stout, abruptly thinned and extended into a slightly long duct at ventroapical portion; diverticulum and spermathecal duct arising from the end of the duct of vagina; diverticulum slightly long, spiral and moderately thinned apically; spermathecal duct distinctly shorter than diverticulum and slightly thinner than basal portion of diverticulum; spermatheca 
composed of a spiral tube which is nearly as long as diverticulum, provided with a thin accessory gland, which is distinctly shorter than the spiral tube of spermatheca; median oviduct situated in middle of vagina.

\section{Remarks}

In the original publication (Wittmer 1982), the aedeagus of species was illustrated in ventral and dorsal views, here it is illustrated again and also in lateral view. Here the genitalia and abdominal sternite VIII of female are illustrated and described for the first time.

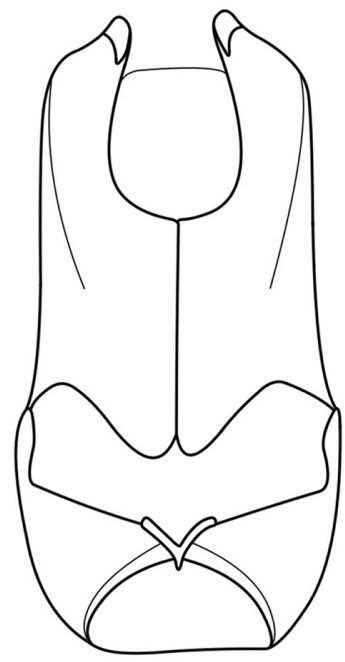

A

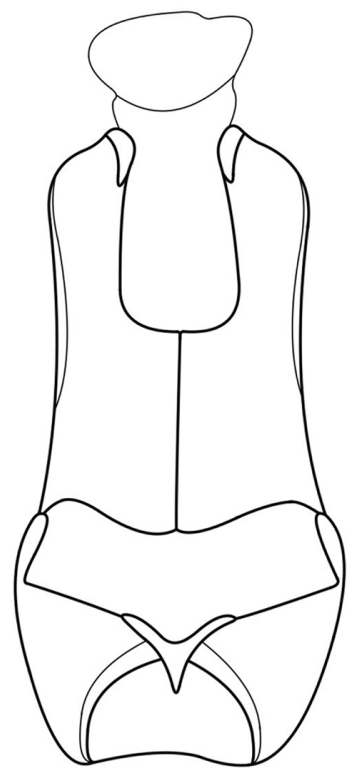

D

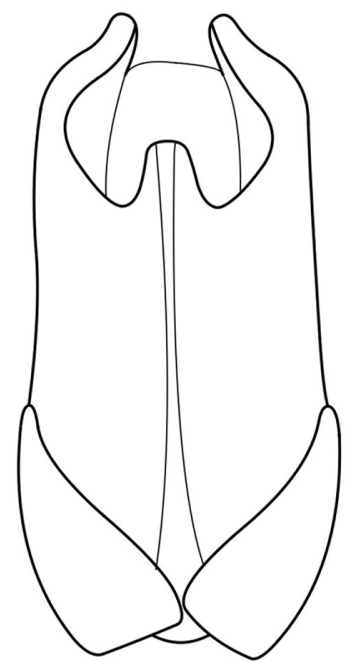

$\mathrm{B}$

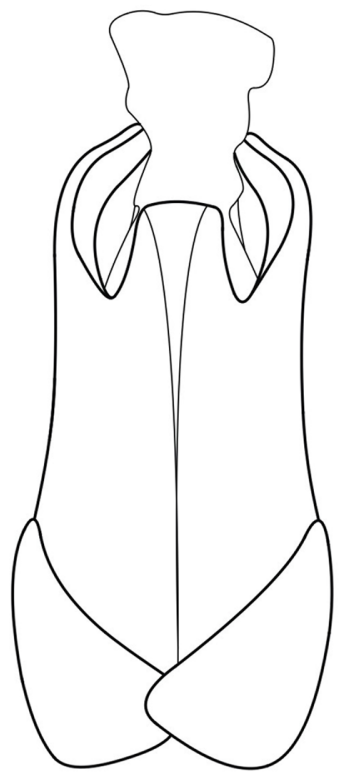

$\mathrm{E}$

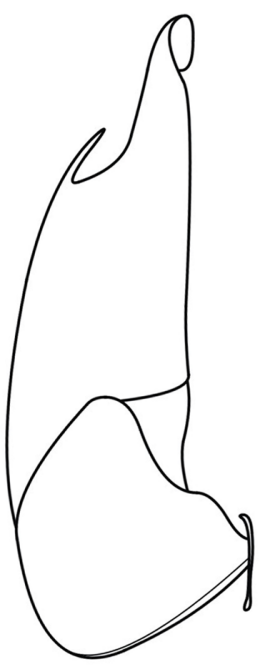

C

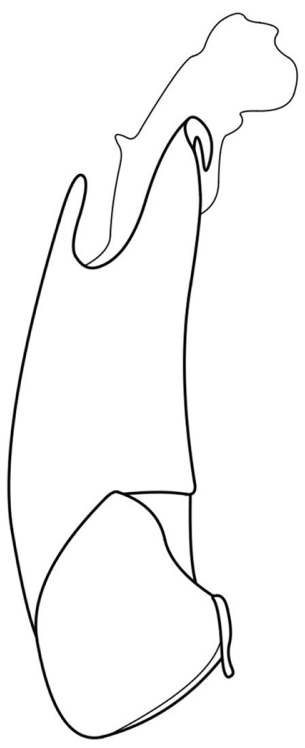

$\mathrm{F}$

Fig. 9. Aedeagus (A, D, G: ventral view; B, E, H: dorsal view; C, F, I: lateral view). A-C. Fissocantharis taipeiana (Wittmer, 1982). D-F. F. uenoi (Wittmer, 1982). Scale bars: $1.0 \mathrm{~mm}$. 


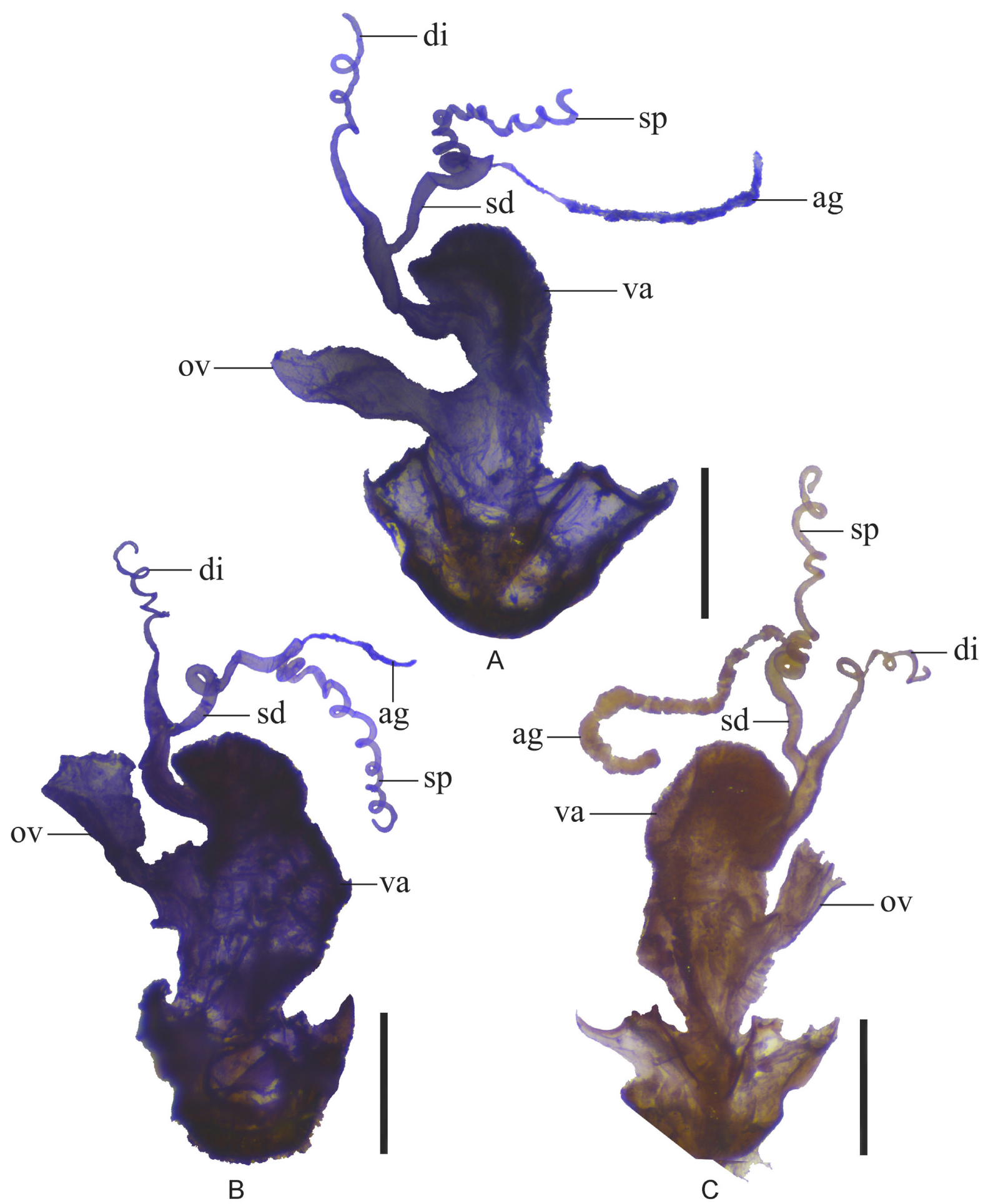

Fig. 10. Female genitalia, lateral view. A. Fissocantharis ssulingensis (Wittmer, 1995). B. F. taipeiana (Wittmer, 1982). C. F. uenoi (Wittmer, 1982). Scale bars: $0.5 \mathrm{~mm}$. 


\section{Distribution}

Taiwan.

Fissocantharis uenoi (Wittmer, 1982)

Figs 9D-F, 10C, 11F

Micropodabrus uenoi Wittmer, 1982: 130, figs 16, 27.

Fissocantharis uenoi - Yang et al. 2012: 52.

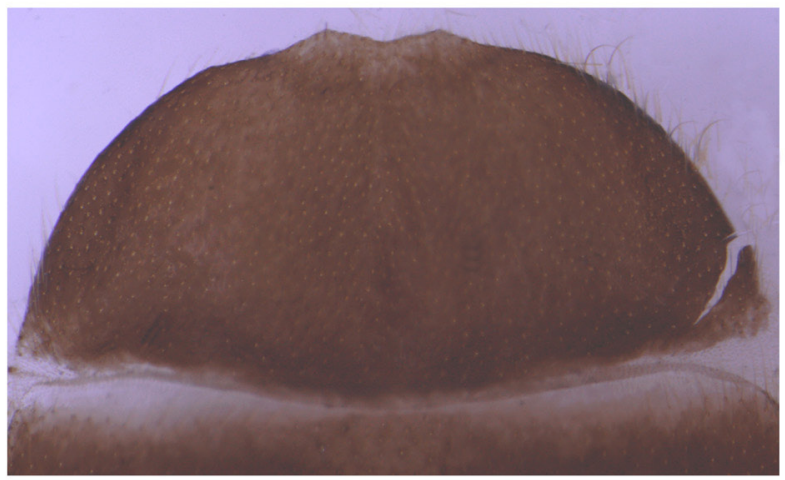

A

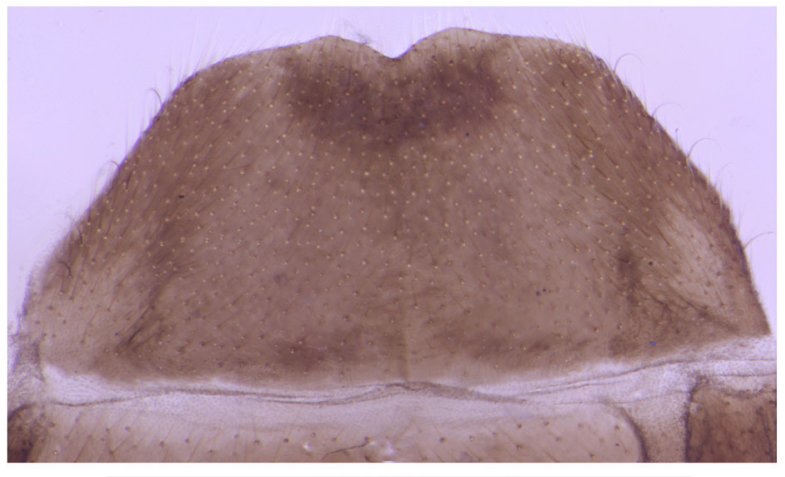

C

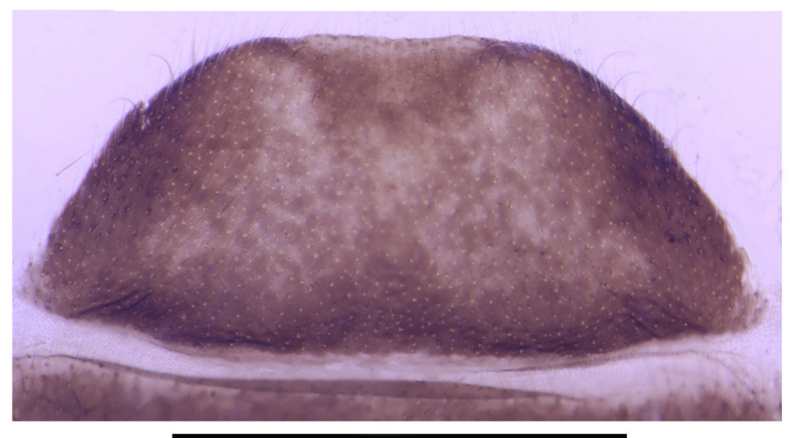

$\mathrm{E}$

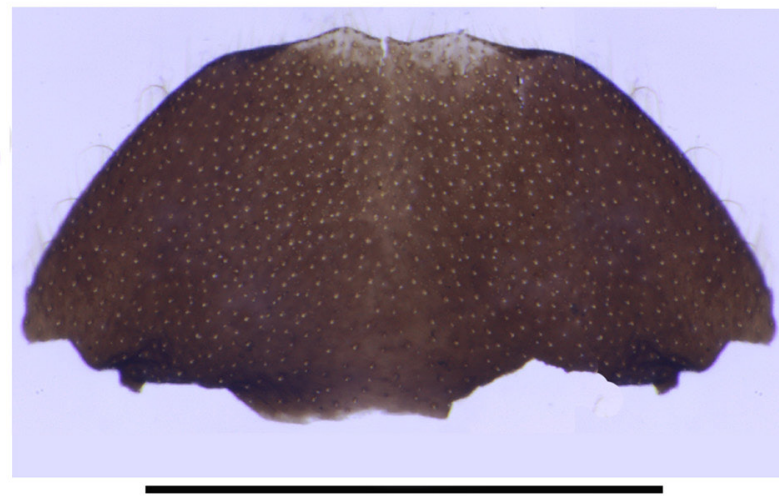

B

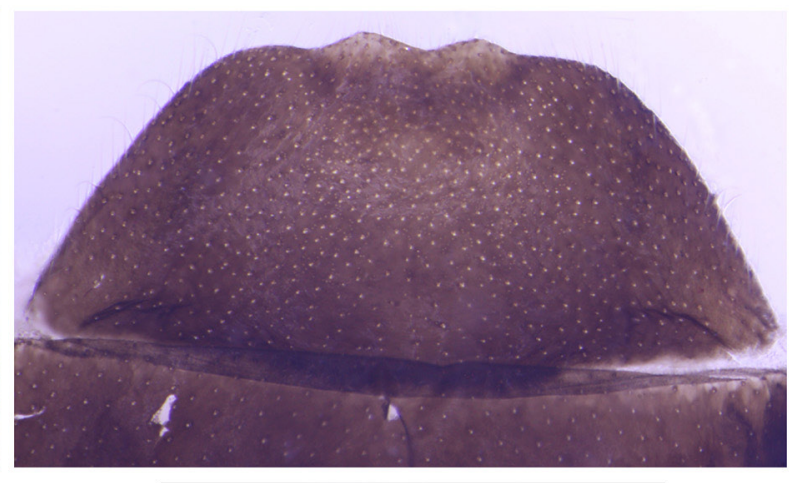

D

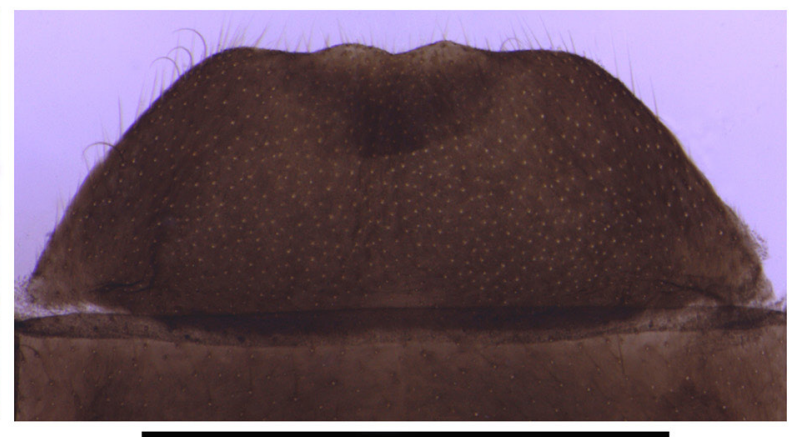

$\mathrm{F}$

Fig. 11. Abdominal sternite VIII of female, ventral view. A. Fissocantharis nantouensis (Wittmer, 1995). B. F. piluchiensis (Wittmer, 1995). C. F. pingtungensis (Wittmer, 1982). D. F. ssulingensis (Wittmer, 1995). E. F. taipeiana (Wittmer, 1982). F. F. uenoi (Wittmer, 1982). Scale bars: $1.0 \mathrm{~mm}$. 

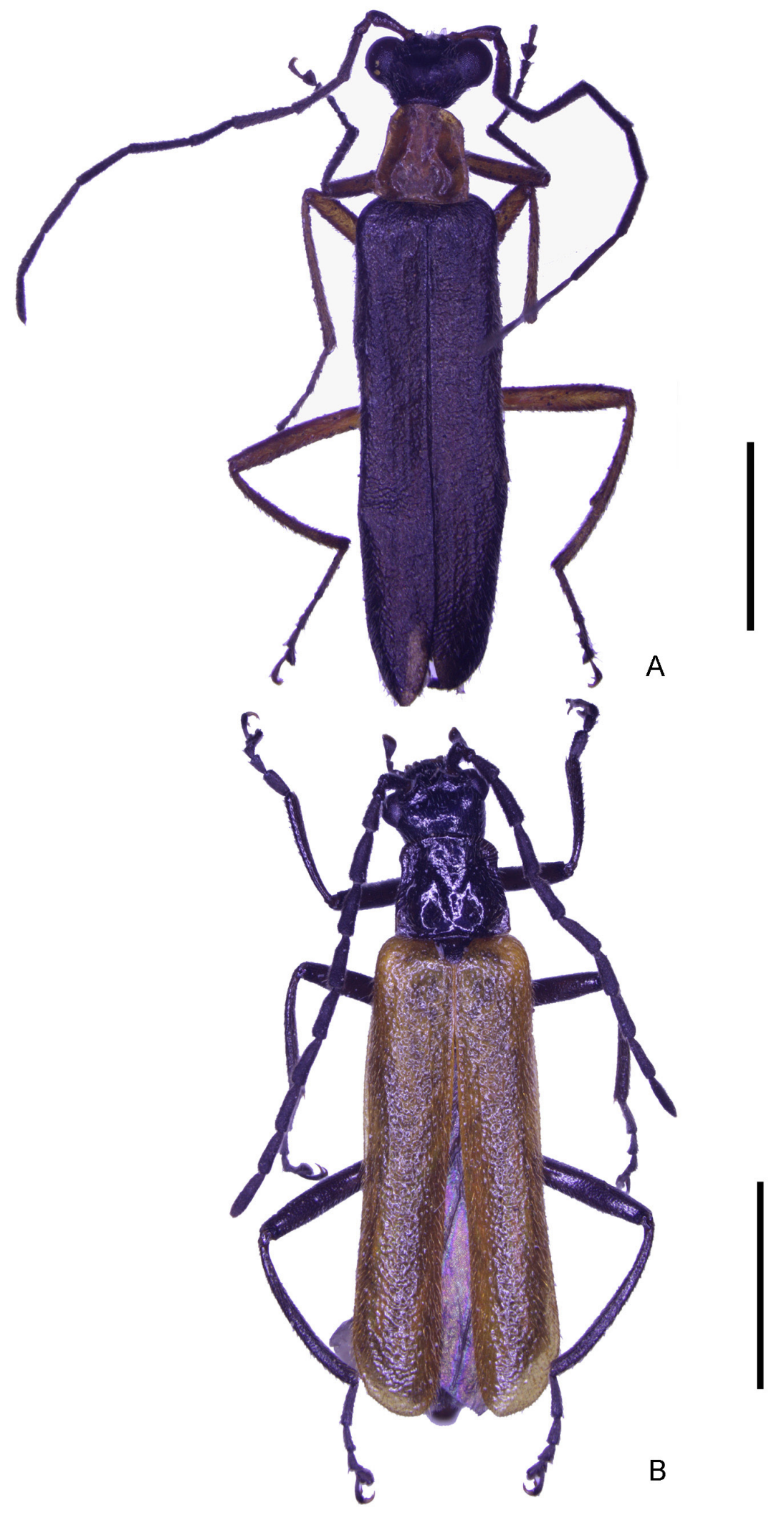

Fig. 12. Male habitus, dorsal view. A. Fissocantharis nigriceps Y. Yang \& Okushima sp. nov. B. Micropodabrus brunneipennis Y. Yang \& Okushima sp. nov. Scale bars: $2.0 \mathrm{~mm}$. 


\section{Material examined}

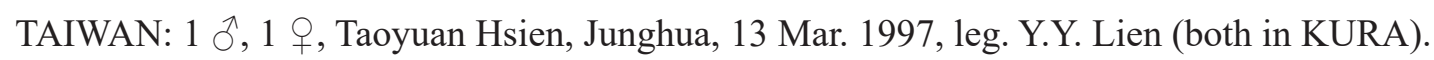

\section{Supplementary description}

AEDEAGUs (Fig. 9D-F). Ventral process of each paramere wide, slightly narrowed apically, moderately hooked at apex; conjoint dorsal plate of parameres moderately developed, about half length of ventral process and as wide as half of the distance between outer margins of ventral processes, slightly narrowed apically, with nearly straight apical margin.

AbDOMinAl STERNITE VIII OF FEMALE (Fig. 11F). Moderately protuberant middle of posterior margin, the middle protuberance moderately and triangularly emarginate at apex, forming a pair of median lobes, which are rounded at apices.

INTERNAL ORGAN OF REPRODUCTIVE SYSTEM (Fig. 10C). Vagina stout, abruptly thinned and extended into a slightly long duct at ventroapical portion; diverticulum and spermathecal duct arising from the end of the duct of vagina; diverticulum slightly long and spiral, moderately thinned apically; spermathecal duct distinctly shorter than diverticulum and slightly thinner than basal portion of diverticulum; spermatheca composed of a spiral tube which is slightly longer than diverticulum, provided with a thin accessory gland which is nearly as long as the spiral tube of spermatheca; median oviduct situated in middle of vagina.

\section{Remarks}

In the original publication (Wittmer 1982), the aedeagus of this species was illustrated only in dorsal view, here it is illustrated again and also in ventral and lateral views. Here the genitalia and abdominal sternite VIII of female are illustrated and described for the first time.

\section{Distribution}

Taiwan.

Genus Micropodabrus Pic, 1920

Micropodabrus Pic, 1920: 6.

Mimopodabrus Wittmer, 1997: 320.

\section{Diagnosis}

This genus is very similar to Fissocantharis, but differentiated from the latter by the aedeagus presenting with laterophyses. The structures of female genitalia are variable, most species are similar to those of Fissocantharis, but some with vagina abruptly and strongly expanded at apical part, spermathecal duct absent, median oviduct situated at base of vagina, such as Micropodabrus multicostata (Wittmer, 1982) and M. nodicornis (Wittmer, 1982).

Micropodabrus chujoi (Wittmer, 1972)

Figs $13 \mathrm{~A}-\mathrm{C}, 15 \mathrm{~A}, 16 \mathrm{~A}$

Kandyosilis chujoi Wittmer, 1972: 136, fig. 20.

Micropodabrus chujoi - Kazantsev \& Brancucci 2007: 256.

Fissocantharis chujoi - Yang et al. 2012: 52. 

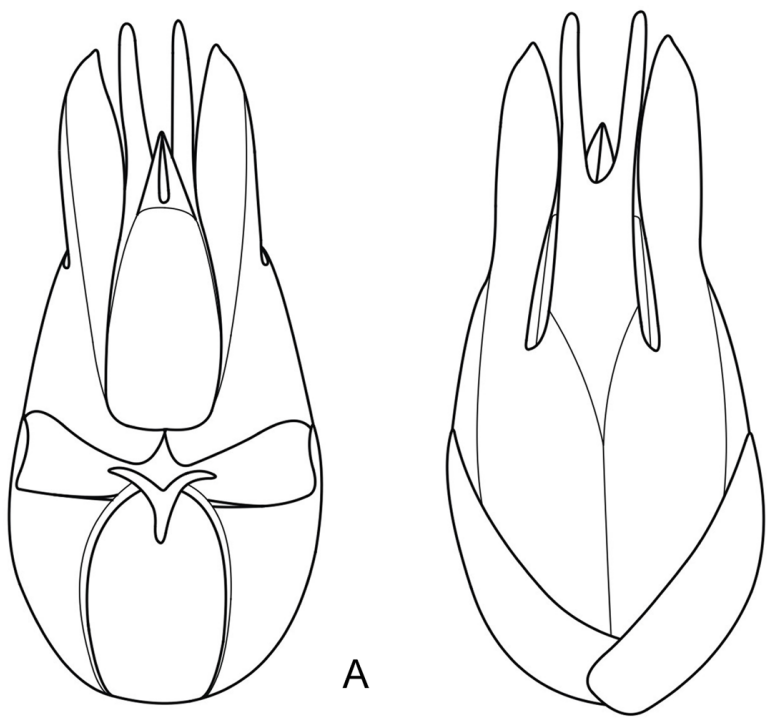

B
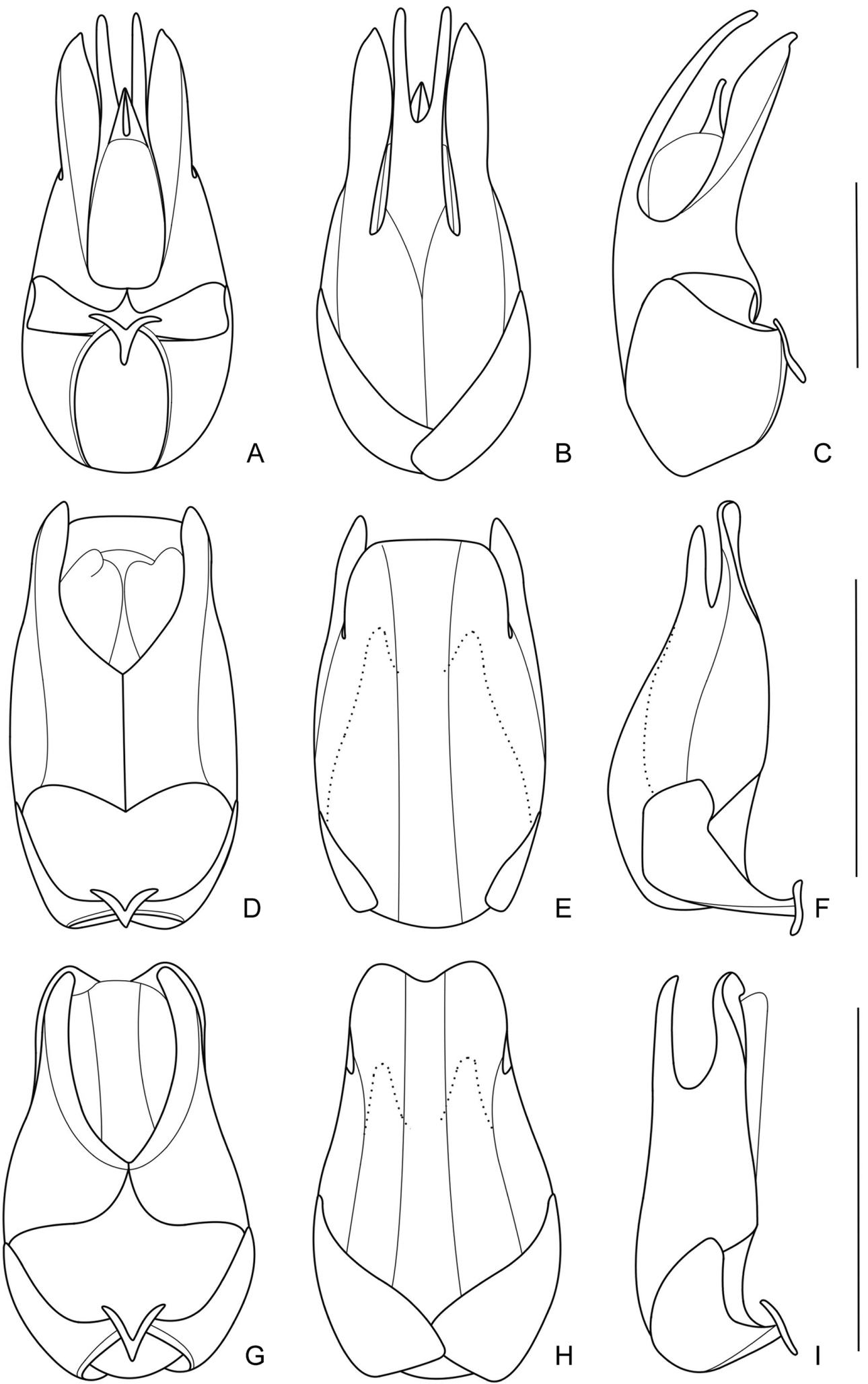

Fig. 13. Aedeagus (A, D, G: ventral view; B, E, H: dorsal view; C, F, I: lateral view). A-C. Micropodabrus chujoi (Wittmer, 1972). D-F. M. mucronata (Wittmer, 1979). G-I. M. multicostata (Wittmer, 1982). Scale bars: $0.5 \mathrm{~mm}$. 


\section{Material examined}

S-TAIWAN: 1 đૈ, Near Liu Kui, Shyk Shan, 12 Jun. 1986, leg. K. Baba; 1 q, Nantou Hsien, Mt. Nengkaoshan, Yunhai, 22 Jun. 1989, leg. M. Satô (both in KURA).

\section{Supplementary description}

AEDEAGus (Fig. 13A-C). Ventral process of each paramere wide, abruptly narrowed at apical portion and pointed at apex; conjoint dorsal plate of parameres well-developed, slightly longer than the length of ventral process and as wide as nearly half of the distance between outer margins of ventral processes, nearly parallel-sided, with apical margin deeply emarginate in middle, the deepness of the middle emargination about half length of conjoint dorsal plate; laterophyses thin, straight and pointed at apices, separated but leaning against each other and sin middle of dorsal side of conjoint dorsal plate.

ABDOMinAl STERNITE VIII OF FEMALE (Fig. 16A). Distinctly protuberant in middle of posterior margin, the middle protuberance widely rounded at apex.

INTERNAL ORGAN OF REPRODUCTIVE SYSTEM (Fig. 15A). Vagina stout, abruptly thinned and extended into a long duct at apex; diverticulum and spermathecal duct arising from the end of the duct of vagina; diverticulum very long, thin and spiral; spermathecal duct distinctly shorter and thicker than diverticulum; spermatheca composed of a spiral tube which is nearly as long as diverticulum, provided with a thin accessory gland, which is much shorter than the spiral tube of spermatheca; median oviduct situated at apex of vagina.

\section{Remarks}

In the original publication (Wittmer 1972), this species was only illustrated with antenna of the male. Here the genitalia of both sexes and abdominal sternite VIII of female are illustrated and described for the first time.

\section{Distribution}

Taiwan.

Micropodabrus mucronata (Wittmer, 1979)

Fig. 13D-F

Kandyosilis mucronata Wittmer, 1979: 333, fig. 5.

Micropodabrus mucronatus -Takahashi et al. 2001: 70.

Fissocantharis mucronata - Yang et al. 2012: 52.

\section{Material examined}

TAIWAN: 1 , Ilan Hsien, Yuanshan, 7 Apr. 2000, leg. T. Mizusawa (KURA).

\section{Supplementary description}

AedeAGus (Fig. 13D-F). Ventral process of each paramere moderately narrowed apically, slightly pointed at apex; conjoint dorsal plate of parameres well-developed, slightly shorter than the length of ventral process and slightly narrower than the distance between outer margins of ventral processes, nearly parallel-sided, with nearly straight apical margin; laterophyses flattened and separated, nearly triangular at apices, adhered to dorsal side of median lobe, distinctly shorter than conjoint dorsal plate. 


\section{Remarks}

In the original publication (Wittmer 1979), this species was only illustrated with male antennae. Here the aedeagus is illustrated and described for the first time.

\section{Distribution}

Taiwan; Ryukyu (Iriomote-jima).

Micropodabrus multicostata (Wittmer, 1982)

Figs 13G-I, 15B, 16B

Kandyosilis multicostata Wittmer, 1982: 136, fig. 34.

Micropodabrus multicostatus - Kazantsev \& Brancucci 2007: 257.

Fissocantharis multicostata - Yang et al. 2012: 52.

\section{Material examined}

TAIWAN: Kaohsiung Hsien: 1 q, Taoyuan, Tengchih, 29 Mar.-1 Apr. 2001, leg. S. Nagashima; 1 ð, same locality, 29 Mar. 2001, leg. K. Okajima; 1 +, same locality, 1 Apr. 2001, leg. K. Okajima (all in KURA).

\section{Supplementary description}

Aedeagus (Fig. 13G-I). Ventral process of each paramere moderately narrowed apically, slightly hooked at apex; conjoint dorsal plate of parameres well-developed, nearly as long as the length of ventral process and slightly wider than the distance between outer margins of ventral processes, slightly widened apically, with apical margin distinctly and triangularly emarginate in middle; laterophyses flattened and separated, nearly triangular at apices, adhered to dorsal side of median lobe, distinctly shorter than conjoint dorsal plate.

Abdominal STERNite VIII of FEMALE (Fig. 16B). Slightly protuberant in middle of posterior margin, the middle protuberance widely triangular at apex.

INTERNAL ORGAN OF REPRODUCTIVE SYSTEM (Fig. 15B). Vagina abruptly and strongly expanded and nearly globular at apical part, under which a very short and thin tube extended; diverticulum, spermatheca and accessory gland arising from the end of the duct of vagina; diverticulum moderately long, thin and spiral; spermathecal duct absent; spermatheca composed of a spiral tube, which is distinctly shorter than diverticulum, provided with a thin accessory gland which is distinctly longer than the spiral tube of spermatheca; median oviduct situated at base of vagina.

\section{Remarks}

In the original publication (Wittmer 1982), this species was only illustrated with male antennae. Here the genitalia of both sexes and abdominal sternite VIII of female are illustrated and described for the first time.

\section{Distribution}

Taiwan. 

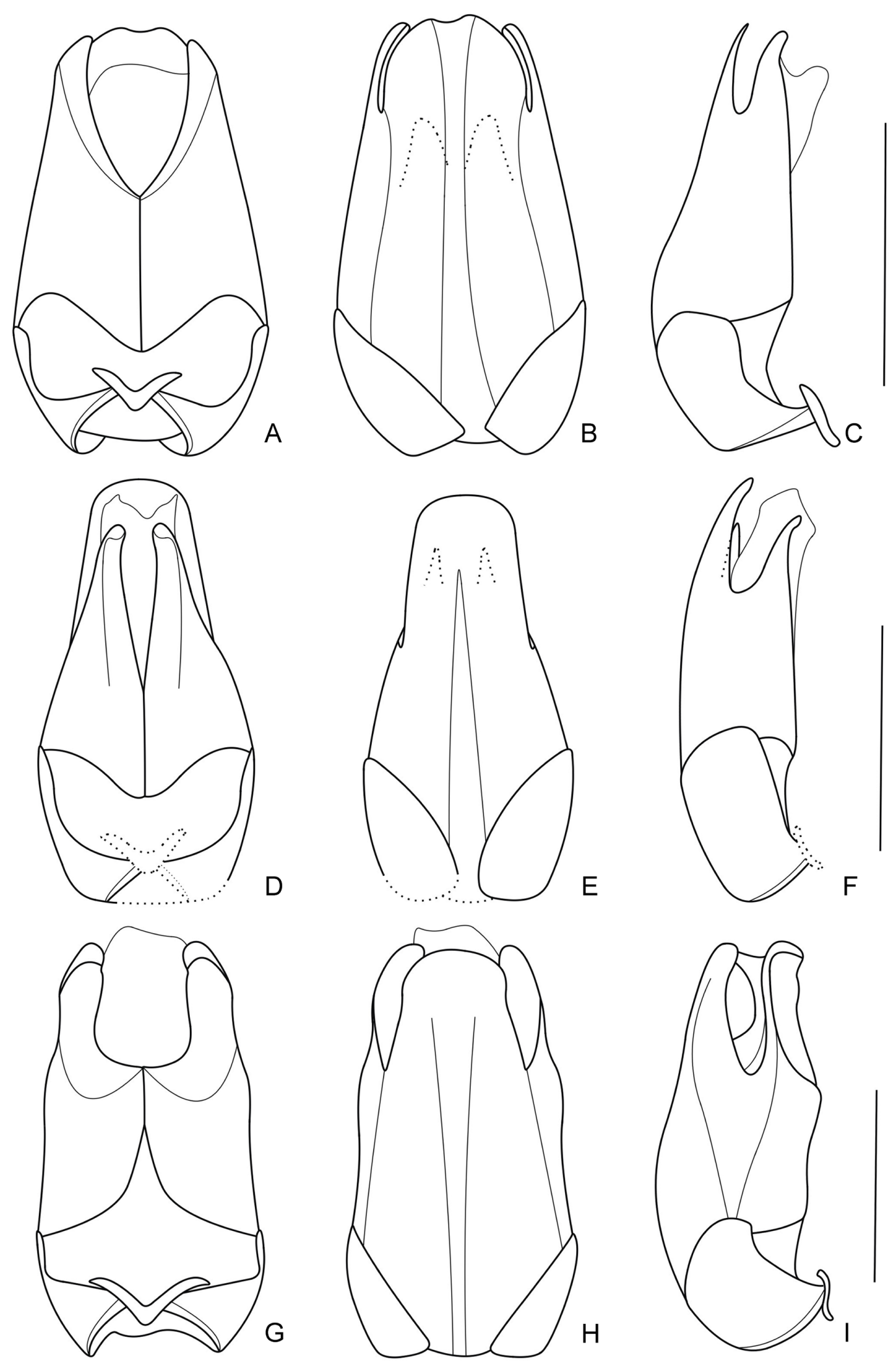

Fig. 14. Aedeagus (A, D, G: ventral view; B, E, H: dorsal view; C, F, I: lateral view). A-C. Micropodabrus nodicornis (Wittmer, 1982). D-F. M. obscurior (Wittmer, 1954). G-I. M. brunneipennis Y. Yang \& Okushima sp. nov. Scale bars: $0.5 \mathrm{~mm}$. 
Micropodabrus nodicornis (Wittmer, 1982)

Figs $14 \mathrm{~A}-\mathrm{C}, 15 \mathrm{C}, 16 \mathrm{C}$

Kandyosilis nodicornis Wittmer, 1982: 137, figs 35, 38, 39.

Micropodabrus nodicornis - Kazantsev \& Brancucci 2007: 257.

Fissocantharis nodicornis - Yang et al. 2012: 52.

\section{Material examined}

TAIWAN: Nantou Hsien: 1 ô, 1 क , Meifeng, 14 May 1994, leg. T. Kishimoto; 1 đo, 1 q, Kwandawshan, 9 Apr. 1996, leg. R. Matsumoto; 1 ðૈ, near Ho Huan Shan, Mei Fon, 2350 m, 10 Jun. 1987, leg. K. Baba (all in KURA).
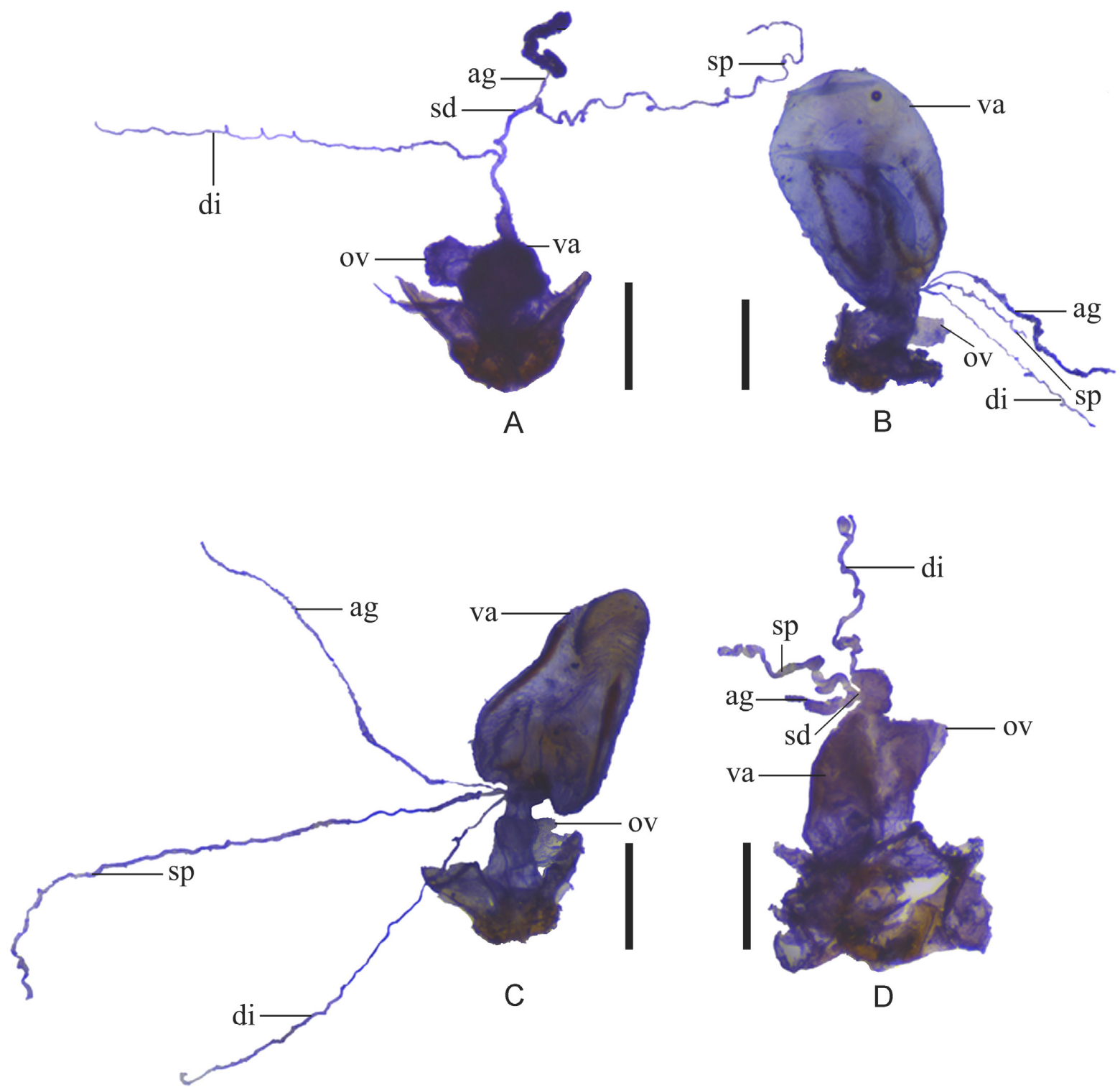

Fig. 15. Female genitalia, lateral view. A. Micropodabrus chujoi (Wittmer, 1972). B. M. multicostata (Wittmer, 1982). C. M. nodicornis (Wittmer, 1982). D. M. obscurior (Wittmer, 1954). Scale bars: $0.5 \mathrm{~mm}$. 


\section{Supplementary description}

Aedeagus (Fig. 14A-C). Ventral process of each paramere moderately narrowed apically, slightly pointed at apex; conjoint dorsal plate of parameres well-developed, nearly as long as the length of ventral process and slightly narrower than the distance between outer margins of ventral processes, slightly narrowed apically, with apical margin slightly and roundly emarginate in middle; laterophyses flattened and separated, nearly triangular at apices, adhered to dorsal side of median lobe, distinctly shorter than conjoint dorsal plate.

Abdominal sternite VIII of Female (Fig. 16C). Moderately and widely emarginate in middle of posterior margin, the middle emargination slightly and triangularly protuberant in middle of bottom margin, lateroapical angles widely rounded.

INTERNAL ORGAN OF REPRODUCTIVE SYSTEM (Fig. 15C). Vagina abruptly and strongly expanded and peach-shaped at apical part, under which a very short and thin tube extended; diverticulum, spermatheca and accessory gland arising from the end of the duct of vagina; diverticulum very long, thin and spiral; spermathecal duct absent; spermatheca composed of a spiral tube which is distinctly longer than diverticulum, provided with a thin accessory gland which is distinctly shorter than the spiral tube of spermatheca; median oviduct situated at base of vagina.

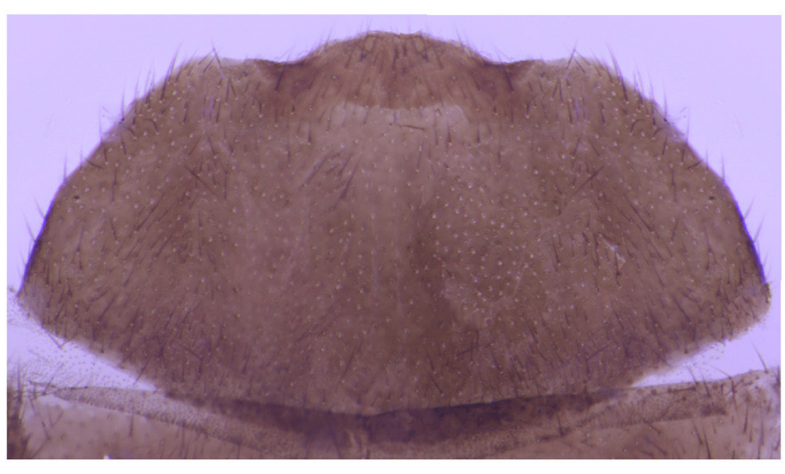

A

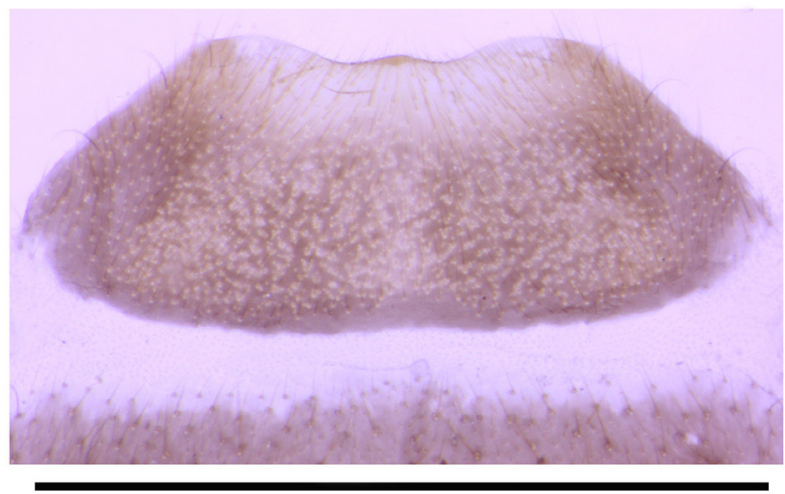

C

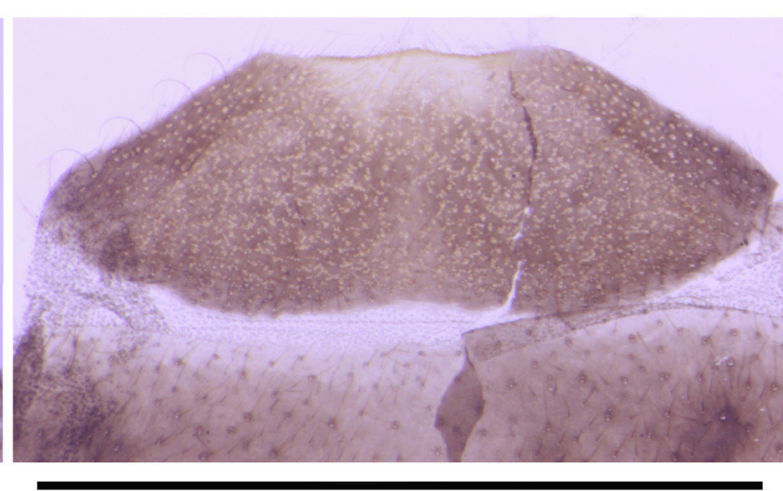

B

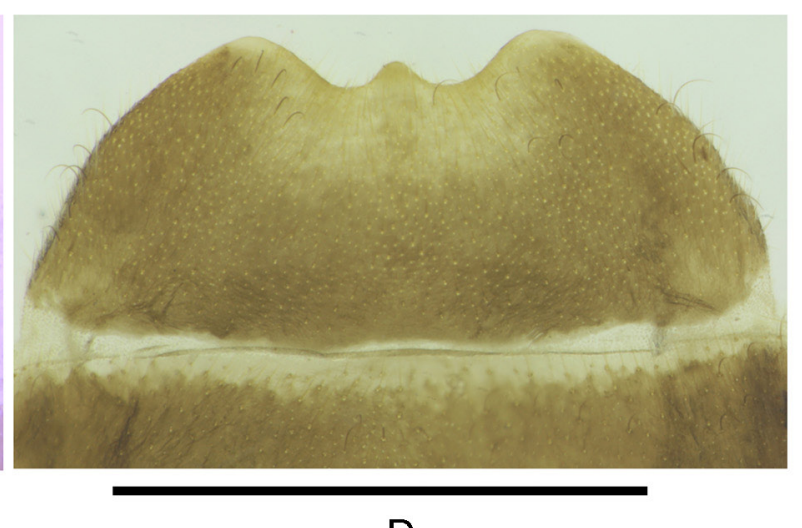

D

Fig. 16. Abdominal sternite VIII of female, ventral view. A. Micropodabrus chujoi (Wittmer, 1972). B. M. multicostata (Wittmer, 1982). C. M. nodicornis (Wittmer, 1982). D. M. obscurior (Wittmer, 1954). Scale bars: $1.0 \mathrm{~mm}$. 


\section{Remarks}

In the original publication (Wittmer 1982), the aedeagus of species was illustrated in ventral and dorsal views, here it is illustrated again and also in lateral view. Here the genitalia and abdominal sternite VIII of female are illustrated and described for the first time.

\section{Distribution}

Taiwan.

Micropodabrus obscurior (Wittmer, 1954)

Figs 14D-F, 15D, 16D

Podabrus obscurior Wittmer, 1954: 272.

Micropodabrus obscurior - Wittmer 1982: 129, figs 10, 25.

Mimopodabrus obscurior - Wittmer 1997: 320.

\section{Material examined}

TAIWAN: Taichung Hsien: 1 đૈ, Kuanshan, Yakou, 2600 m, 11 Jun. 1989, leg. M. Satô; 4 q $q$, Anmashan, 16 Jun. 1989, leg. M. Satô; 1 q, same data, 14 Jun. 1989; 1 q, same data, 15 Jun. 1989; Nantou Hsien: 1 , , Kwandawshan, 9 Apr. 1996, leg. R. Matsumoto (all in KURA).

\section{Supplementary description}

AEDEAGus (Fig. 14D-F). Ventral process of each paramere distinctly narrowed apically, slightly hooked at apex; conjoint dorsal plate of parameres well-developed, distinctly longer than the length of ventral process and wider than the distance between outer margins of ventral processes, slightly narrowed apically, with nearly straight apical margin; laterophyses separated, thin, nearly straight and pointed at apices, situated in middle of dorsal side of median lobe, distinctly shorter than conjoint dorsal plate.

ABDominal STERNite VIII of FEMALE (Fig. 16D). Distinctly and widely emarginate in middle of posterior margin, the middle emargination moderately and triangularly protuberant in middle of bottom margin, lateroapical angles narrowly rounded.

INTERNAL ORGAN OF REPRODUCTIVE SYSTEM (Fig. 15D). Vagina stout, abruptly thinned and extended into a short and thick duct at apex; diverticulum and spermathecal duct arising from the end of the duct of vagina; diverticulum moderately long, spiral and abruptly thinned apically; spermathecal duct very short, distinctly thinner than basal portion of diverticulum; spermatheca composed of a spiral tube, which is slightly shorter than diverticulum, provided with a thin accessory gland, which is distinctly shorter than the spiral tube of spermatheca; median oviduct situated at apex of vagina.

\section{Remarks}

The aedeagus was illustrated in ventral view by Wittmer (1982), here it is illustrated again and also in dorsal and lateral views. Besides, the genitalia and abdominal sternite VIII of female are illustrated and described for the first time.

\section{Distribution}

Taiwan. 
Micropodabrus brunneipennis Y. Yang \& Okushima sp. nov. urn:1sid:zoobank.org:act:E9724035-6C90-4A46-A2F7-DE20B2534A5B

Figs 12B, 14G-I

\section{Diagnosis}

This species could be easily differentiated from other species of Micropodabrus by its brown elytra and the structures of aedaegus: ventral process of each paramere wide, laterophyses strongly sclerotized and bent dorsally at apices.

\section{Etymology}

The specific epithet is derived from the Latin brunneus (brown) and penna (wing), referring to its brown elytra.

\section{Material examined}

Holotype

TAIWAN: Õ, Nantou Hsien, Meifeng, alt. 2100 m, 28 Nov. 1995, leg. M. Owada (NMNS).

\section{Description}

Male (Fig. 12B)

Body length: $6.5 \mathrm{~mm}$; width: $1.5 \mathrm{~mm}$.

BoDy. Black and shiny, elytra brown. Body densely covered with recumbent gray pubescence, pronotum and elytra with brown pubescence, which is slightly longer on the latter.

HEAD. Rounded, temples slightly narrowed posteriorly, surface densely and coarsely punctate; eyes moderately protruding, head width across eyes slightly wider than anterior margin of pronotum; terminal maxillary palpomeres subtriangular, widest nearly in middle, acurate on apical parts of inner margins, acute at apices; antennae filiform, slightly thickened, extending to elytral midlength, antennomeres II nearly as long as wide, III about twice as long as II, IV about one-third longer than III, XI slightly longer than X, pointed at apices.

Pronotum. Subquadrate, slightly wider than long, slightly widened posteriorly, anterior margin arcuate, lateral margins sinuate, posterior margin narrowly bordered and bisinuate, anterior angles rounded, posterior angles nearly rectangular; disc distinctly convex on posterolateral parts, surface lustrous, sparsely and finely punctate.

ELYTRA. About 3.0 times as long as humeral width, 4.5 times longer than pronotum, nearly parallelsided, disc densely and coarsely punctate.

LEGS. With all tarsal claws bifid.

Aedeagus (Fig. 14G-I). Ventral process of each paramere wide, slightly sinuate at outer margins, moderately hooked at apex; conjoint dorsal plate of parameres well-developed, slightly shorter than the length of ventral processes and distinctly narrower than distance between outer margins of ventral processes, slightly sinuate in middle of lateral margins, with nearly straight apical margin; laterophyses separated, strongly sclerotized and bent dorsally at apices, situated in middle of dorsal side of median lobe, as long as conjoint dorsal plate.

\section{Female}

Unknown. 


\section{Distribution}

Taiwan.

\section{Discussion}

Apart from the characters provided in traditional description and comparisons, Fissocantharis laticornis differs from other species of Fissocantharis by the female genitalia: vagina is nearly global, abruptly narrowed and extended into a moderately long duct near middle of ventral side; median oviduct is situated at base of vagina. Other species of this genus share the characters summarized in the generic diagnosis, but can be easily differentiated by the shapes of antennae in males, see the keys by Wittmer (1982, 1995).

The genus Micropodabrus differs from Fissocantharis only in the aedeagus presenting laterophyses (Yang et al. 2009). Based on this diagnosis, the following reconfirmed combinations are proposed, M. chujoi (Wittmer, 1972), M. mucronata (Wittmer, 1979), M. multicostata (Wittmer, 1982) and M. nodicornis (Wittmer, 1982). These species were all originally described in Kandyosilis Pic, 1929, and another 4 species, F. biimpressa (Wittmer, 1982), F. curvicornis (Wittmer, 1997), F. subniger (Wittmer, 1972) and F. taiwana (Wittmer, 1979), which were also originally or once placed in Kandyosilis, are considered in incertaesedis now. The status of these taxa may be clarified in the future when material is available in the study.

The species of Micropodabrus can be distinguished using the key provided by Yang et al. (2009). The shapes of laterophyses of the aedeagus are variable among the species within this genus. This variation can be also observed well in the genus Themus Motschulsky, 1860. Accordingly, the female genitalia are also variable, particularly the shape of the vagina and the position of median oviduct.

\section{Acknowledgments}

We are grateful to the late Dr. Michel Brancucci (NHMB) for giving some guidance to the first author in studying on the taxonomy of Cantharidae. Thanks are due to Mr. John MacDermott (USA) for correcting our English of the manuscript. The present study is supported by the National Natural Science Foundation of China (Nos. 31172135, 41401064), the Knowledge Innovation of Chinese Academy of Sciences (No. KSCX2-EW-Z-8) and the National Student Innovation Training Program of China (No. 201510075015).

\section{References}

Kazantsev S.V. \& Brancucci M. 2007. Cantharidae. In: Löbl I. \& Smetana A. (eds) Catalogue of Palaearctic Coleoptera, vol. 4: 234-298. Apollo Books, Stenstrup, Denmark.

Nakane T. 1992. Notes on some little-know beetles (Coleoptera) in Japan. 9. Kita-Kyūshū no Konchū 39 (2): 73-79.

Pic M. 1910. Malacodermes et hétéromères nouveaux d'Afrique et d'Asie. Le Naturaliste 32: 271-272.

Pic M 1920. Nouveautés diverses. Mélanges Exotico-Entomologiques 32: 1-28.

Pic M. 1921a. Nouveautés diverses. Mélanges Exotico-Entomologiques 33: 1-32.

Pic M. 1921b. Contribution à l'étude des Lycides. L'Échange, Revue Linnéenne 37 (404-406): 1-12.

Pic M. 1922. Nouveautés diverses. Mélanges Exotico-Entomologiques 37: 1-32.

Pic M. 1926. Nouveaux coléoptères du globe. Bulletin de la Société Entomologique de France 51: 235-238. 
Pic M. 1927. Coléoptères de l’Indochine. Mélanges Exotico-Entomologiques 49: 1-36.

Pic M. 1929. Malacodermes exotiques (Suite). L'Échange, 65 [hors-texte] (437-438): 69-76.

Pic M. 1955. Coléoptères du globe (Suite). L’Échange, Revue Linnéenne 71: 7-11.

Švihla V. 2004. New taxa of the subfamily Cantharinae (Coleoptera, Cantharidae) from southeastern Asia with notes on other species. Entomologica Basiliensia 26: 155-238.

Švihla V. 2005. New taxa of the subfamily Cantharinae (Coleoptera: Cantharidae) from south-eastern Asia with notes on other species II. Acta Entomologica Musei Nationalis Pragae 45: 71-110.

Takahashi N., Okushima Y. \& Ichita T. 2001. Cantharid beetles Coleoptera, Cantharidae of Aomori Prefecture, northern Honshu, Japan, V. Bulletin of the Kurashiki Museum of Natural History 16: 65-78.

Wittmer W. 1938. 3. Beitrag zur Kenntnis der indo-malayischen Malacodermata (Col.). Treubia 16 (3): 301-306.

Wittmer W. 1954. Zur Kenntnis der Cantharidae der Insel Formosa. (19. Beitrag zur Kenntnis der palaearktischen Malacodermata, Col.). Revue Suisse de Zoologie 61: 271-282.

Wittmer W. 1969. Synonymische und systematische Notizen über Coleopteren. Mitteilungen der Schweizerischen Entomologischen Gesellschaft 42 (1-2): 126-134. http://doi.org/10.5169/seals-401586

Wittmer W. 1972. 55. Beitrag zur Kenntnis der palaearktischen Cantharidae und Malachiidae (Col.). Entomologischen Arbeiten aus dem Museum G. Frey 23: 122-141.

Wittmer W. 1979. 64. Beitrag zur Kenntnis der palaearktischen Cantharidae, Phengodidae und Malachiidae (Col.). Entomologica Basiliensia 4: 327-346.

Wittmer W. 1982. Die Familie Cantharidae (Col.) auf Taiwan (1. Teil). Entomological Review of Japan 37: 119-140, pls. 4-8.

Wittmer W. 1988. Zur Kenntnis der Cantharidae (Coleoptera) Chinas und der angrenzenden Länder. Entomologica Basiliensia 12: 343-372.

Wittmer W. 1993. Zur Kenntnis der palaearktischen und indo-malaiischen Cantharidae (Coleoptera). Entomologica Basiliensia 16: 203-253.

Wittmer W. 1995. Neue Cantharidae (Col.) aus dem indo-malaiischen und palaearktischen Faunengebiet mit Mutationen. Entomologica Basiliensia 18:109-169.

Wittmer W. 1997. Neue Cantharidae (Col.) aus dem indo-malaiischen und palaearktischen Faunengebiet mit Mutationen. 2. Beitrag. Entomologica Basiliensia 20: 223-365.

Yang Y.X., Brancucci M. \& Yang X.K. 2009. Synonymical notes on the genus Micropodabrus Pic and related genera (Coleoptera, Cantharidae). Entomologica Basiliensia et Collectionis Frey 31: 49-54.

Yang Y.X., Okushima Y. \& Yang X.K. 2012. Synonym, new species and checklist of the genus Fissocantharis Pic from Taiwan (Coleoptera, Cantharidae). Zootaxa 3262: 46-53.

Yang Y.X., Su J.Y. \& Yang X.K. 2014. Taxonomic note and description of new species of Fissocantharis Pic from China (Coleoptera, Cantharidae). Zookeys 443: 45-59. http://dx.doi.org/ $\underline{10.3897 / \text { zookeys.443.8309 }}$

Yang Y.X., Li L.M., Guan K.L. \& Yang X.K. 2015. Taxonomy of Fissocantharis Pic (Coleoptera, Cantharidae) from Guangxi, China, with description of six new species. Zookeys 489: 95-123. http:// dx.doi.org/10.3897/zookeys.489.9153 
Manuscript received: 13 February 2016

Manuscript accepted: 5 April 2016

Published on: 14 November 2016

Topic editor: Koen Martens

Desk editor: Natacha Beau

Printed versions of all papers are also deposited in the libraries of the institutes that are members of the EJT consortium: Muséum national d'Histoire naturelle, Paris, France; Botanic Garden Meise, Belgium; Royal Museum for Central Africa, Tervuren, Belgium; Natural History Museum, London, United Kingdom; Royal Belgian Institute of Natural Sciences, Brussels, Belgium; Natural History Museum of Denmark, Copenhagen, Denmark; Naturalis Biodiversity Center, Leiden, the Netherlands. 